09/RT/14

Páipéar Taighde Teicniúil

Research Technical Paper

ECB Monetary Operations and the Interbank Repo Market

Peter G Dunne, Michael Fleming and Andrey Zholos 


\title{
ECB Monetary Operations and the Interbank Repo Market
}

\author{
Peter G. Dunne \\ Central Bank of Ireland. \\ Michael J. Fleming \\ Federal Reserve Bank of New York. \\ Andrey Zholos \\ Barclays Capital.
}

July 2014

\begin{abstract}
We examine the relationship between the outcomes of ECB monetary policy operations and interbank market trading of reserves using sovereign bonds as collateral. In a pre-crisis period we find significant interactions between these funding sources but the relation is very variable within maintenance periods and around the year-end. Whilst controlling for these seasonal effects we find that interbank market was highly sensitive to interest rate increases immediately prior to the financial crisis. Focusing on the crisis period - but before the Lehman Brothers collapse - we show that the potential for easing interbank market tensions through flexible allotment at auctions was underutilised. Aggressive bidding in auctions had strong price effects that encouraged continued reliance on a stressed interbank market. The analysis highlights the advantages of using variable-rate flexible-allotment operations as part of a future tapering of non-standard measures rather than moving directly to variable-rate auctions with (effectively) fixed allotments. This would produce beneficial incentives while at the same time permitting substantial control over liquidity conditions.
\end{abstract}

KEYWORDS: Repo, Funding, Liquidity, Monetary Policy, Reserve Management. JEL Classification: E43, E44, E52, E53, G12, G14.

Views expressed in this paper are those of the authors and not necessarily those of the Federal Reserve Bank of New York, the Federal Reserve System or the ECB/ESCB. We are grateful for comments from Patrick Haran, Julien Idier, Rajkamal Iyer, Danielle Kedan, Angelo Ranaldo, Jan Scheithauer, Johannes Skjeltorp, Thomas Werner and Jan Wrampelmeyer. This paper was presented at the ECB workshop on, "Structural Changes in Money Markets: Implications for Monetary Policy Implementation," in Oct 2013 and we thank participants for comments. We thank ICAP for providing BrokerTec repo data and their representatives; John Edwards, Antoine Kohler, Moira Salzen and Dermot Doherty for practical help. We processed the data using specialized software developed by KX-Systems - Palo Alto, provided through their European agents First Derivatives, N. Ireland. 


\section{Non-Technical Summary}

An important element of monetary policy is the imposition of reserve requirements on banks (i.e., requirements to hold a daily average amount of reserves within each reserve maintenance period). In the Euro Area reserve requirements are set equal to a proportion of banks' liquid liabilities (mainly demand deposit accounts). This requirement creates a demand for reserves (they can be considered working capital) and the ECB conducts auctions at regular intervals within reserve maintenance periods to supply these. Official reserves facilitate the real-time settlement of transactions between customers of different banks. Such transactions are unpredictable and they can push a bank's reserves away from what is likely to result in adherence to the average requirements. In normal conditions reserve surprises are mostly symmetric (causing one bank to have a positive shock while another has a negative one) and these shocks can usually be counteracted by interbank transactions where the surplus bank lends to the deficit bank. Interbank transactions can be unsecured or secured against collateral (i.e., repurchase agreements). Our analysis focuses on the relationship between the interbank trading of reserves secured against sovereign bonds as collateral and the behavior of banks in official auctions.

The requirement to hold short term reserves reduces the amount that banks can moreprofitably lend for longer maturity. An increase in the efficiency of the interbank market can therefore release capital for lending. The deepening of the integration of European financial markets from 1999 to 2007 and the increasingly widespread participation of banks in interbank electronic trading venues, most likely contributed to increased efficiency in the sharing of reserves before the crisis. This may have led to less cautious management of reserves and a greater reliance on the interbank market. These developments, in combination with movements towards non-deposit based funding, a more leveraged banking sector and an accommodative monetary policy stance, may have been responsible for the significant increase in long term lending that was observed during the pre-crisis period. We begin our study by analysing how interbank activity was related to behaviour at auctions during this period and we assess the effects of a tightening of monetary policy just before the crisis.

It is known that some banks in the pre-crisis period had small reserve requirements but large amounts of low-quality lending (sourcing funding from corporate bond investors rather than customer deposits). They also managed these small amounts of reserves aggressively 
with high dependence on the interbank market. Such banks were the source of severe increases in counterparty risk during the financial crisis. This led to a widespread reluctance to trade reserves (particularly in unsecured transactions) and it reduced the value and acceptability of some types of collateral. This also led to increased demand for official funding and a change in behaviour of banks, at official auctions (with much more aggressive bidding by some banks).

Auction policy initially responded to crisis-related pressures by relaxing the amounts allotted in auctions. After the Lehman crisis there was another change in policy (a move to fixed-rate full-allotment auctions). We examine the effects of these changes through a structural analysis of the relationship between amounts sought at auctions and amounts traded in the interbank market. We control for collateral quality effects and interbank market conditions. Our results indicate that the fixed-rate full-allotment policy discourages re-intermediation and we suggest that a move to variable rate auctions with flexible allotment quantity would be beneficial in encouraging banks to restore normal interbank trading relations. It would also incentivise banks to conduct balance sheet repairs, and eventually, to engage in re-capitalisations through new equity issuances. 


\section{Introduction}

Notwithstanding the high-frequency evidence provided by Brunetti, Filipo and Harris (2009) for the unsecured interbank market, there is a shortage of conclusive evidence (for the case of ECB operations) of a well-established relation between the behaviour of banks in monetary operations and their interbank market activities. ${ }^{1}$ Demiralp and Carpenter (2006a, 2006b) investigate, and find evidence of, an anticipation effect in the federal funds market in the US around target rate announcements and interventions, as well as liquidity effects on the last days of maintenance periods, but this is quite a different institutional setting to that of the Euro Area.

Limited information about this relation casts doubt on our current understanding of the reliability of the mechanism through which monetary policy is supposed to operate. We also know too little about how this mechanism was affected by the financial and sovereign debt crises of recent years and the policy responses to them. A better understanding of this relation and how it has changed throughout the crisis is crucial to inform the debates about how best to return to normal operations and about whether changes are needed in the operational framework.

For the case of the Euro Area we examine how the collateralised trading of reserves in the interbank market and the outcomes of monetary policy reserve operations are related in three main regimes. Firstly, for the non-crisis regime, we estimate the causal links between bidding aggressiveness in monetary operations and interbank trading activity subject to maintenance period seasonality. Demiralp and Carpenter (2006a, 2006b) found that, in the US, monetary policy affected interbank market behaviour indirectly - as a result of interest rate changes eventually feeding back to reserve needs. This causal direction is appropriate (in the sense that the responses of investment and saving plans to real interest rates drives interbank transaction needs). We begin our analysis by uncovering evidence suggesting that - in the period immediately preceding the interbank market disruptions of mid-2007

\footnotetext{
${ }^{1}$ In the case of Brunetti et al (2009) the evidence presented is only relevant to a very high frequency interaction between interbank activity and auction outcomes/behaviour during the early stages of the financial crisis. Evidence of the effects of the specific unusual long-term operations conducted by the ECB have been considered by Mancini, Ranaldo and Wrampelmeyer (2013) and they argue that official liquidity provided through very long-term LTRO auctions has no significant effects on interbank activity or rates which they interpret as a type of liquidity trap.
} 
- policy rate increases led to more severe, and more sudden, contractions in interbank market activity than would have been expected if investment and saving plans were the main driving forces of such transactions. This is consistent with an alternative causal effect - i.e., contagion arising from the deterioration in the credit quality of banks' assets, when interest rates rose, leading to increased counterparty risk and reduced transactions within the interbank market. We argue that timely information about this reaction of interbank activity could have acted as a warning signal that monetary policy was not working appropriately.

The prolonged financial crisis of recent years can be divided into a number of regimes but our analysis is mainly relevant for the first of these. We show that there is little relationship between monetary operations and activity in the interbank market for the period after the introduction of fixed-rate full-allotment auctions. This period can be assessed by just explaining the variation in the fraction of activity that takes place in the interbank market as a function of factors that allow banks to transact with each other at rates that improve on the fixed rate available in auctions (e.g., collateral quality and counterparty credit risk measures). Some of this analysis is already included in the work by Mancini et al (2013) and we do not add to that topic.

The first important crisis regime is the period from mid-2007 to immediately before the Lehman Brothers collapse in September 2008. This period was characterised by frequent liquidity contractions within the interbank market, and this (i), changed how banks behaved in monetary policy operations and (ii), prompted some flexibility in how monetary policy operations were conducted. Some banks were prepared to bid very aggressively in reserve auctions while the amount of reserves that was allotted in auctions was permitted to rise above what would normally have been regarded as sufficient to satisfy average reserve requirements.

Absent the effects of the actual increase in allotment quantity at auctions in this period, the more aggressive bidding behaviour (as described by Drehmann and Nikolau 2013) can be regarded as having two competing effects. Firstly, it distributed relatively more reserves to weaker banks and eased localised liquidity difficulties. This would have reduced the need for interbank trading by banks that received such allocations. Secondly, it raised the average cost of official funding for other banks (and it increased the risks that these banks would be outbid and therefore not allocated any of the reserves supplied at auctions). 
Anecdotal evidence also points to the emergence of a stigma attached to obtaining funding through these more flexible and more expensive operations.

Banks with sufficient access to good collateral were therefore incentivised (through the price effect and their avoidance of a stigma effect) to resort more heavily to the interbank repo market. Whether the more targeted allocation of reserves to the most-needy banks or the relative price effect was more important in explaining the changes in interbank trading is a matter for empirical investigation. This provides us with an exceptional opportunity to measure the effects of flexible allocation of reserves in official operations (conducted as variable rate auctions) and it motivates the case for such operations during the renormalisation process so as to maintain sufficient liquidity while incentivising structural reform in banks' asset and liability management exercises.

Our analysis is made possible by the use of detailed information from the BrokerTec repo trading platform. BrokerTec repo trading activity represents about half of all automated trading activity in repos that use Euro Area sovereign bonds as collateral and about 15\% of all repo trading by main Euro Area banks. To conduct the analysis we reconstruct the order books of individual repo markets over a nine year period (2,381 trading days). This involved processing almost 104 million order book records. From these books we derive common measures of liquidity and market quality and we produce statistics concerning how diffuse these conditions are across the various collateral types and across the different terms of repo transactions. However, the main endogenous interbank variable used in the core relationship is trading volume.

This paper contributes to a more general literature concerned with repo markets and monetary policy. It adds to the already extensive analysis of the Euro Area repo market by Mancini, Ranaldo and Wramplemeyer (2013). It also contributes to work on monetary policy operations of central banks and, in particular, of the ECB. Borio and Nelson (2008) provide a general background to the operational effects of the financial turmoil of 2007 and, Cour-Thimann and Winkler (2013) provide a comprehensive description and assessment of the ECB's non-standard monetary policy measures. In Bindseil, Nyborg and Strebulaev (2009), weekly repo auctions of the ECB are examined to gain an understanding of how bidding strategies affect auction outcomes. Their analysis includes an indirect assessment of how interbank markets (specifically, interest rates in the unsecured interbank market) affect auction behaviour. Drehmann and Nikolau (2009, 2013) examine bidding behavior 
in ECB funding operations during the crisis and find that it is affected by the increased individual refinancing motive, the increased attractiveness of the ECB's tender operations due to its collateral framework and banks' bidding more aggressively to avoid being rationed at the marginal rate or completely excluded from supply if the marginal rate turns out to be very high relative to expectations. We show that this behavior reflects deteriorating conditions within the interbank repo market (where banks were previously able to plan their liquidity provision) and it produced a protracted policy response that had further feedback effects within the post-auction interbank repo market.

We begin our analysis by outlining the linkages between interbank repo market activity and the behaviour of participants in official refinancing operations. A structural specification for the relationship is then presented and issues of stationarity and the handling of an irregular seasonality due to the maintenance period are discussed. The broad changes in liquidity conditions that occur in the interbank repo market and the main structural changes in ECB intervention policy before and during the crisis are then discussed. This includes a discussion of the data used in the analysis including variables used to explain structural change in the relationship during the crisis period such as; an index of countryspecific changes in bank CDS spreads, the EURIBOR-OIS spread, sovereign bond CDS spreads and microstructure variables from the interbank market. We then present results and conclude with a discussion of policy implications and proposals for further work.

\section{Interbank Markets, ECB Auctions and Monetary Policy}

In normal circumstances the ECB conducts monetary policy by imposing reserve requirements on banks while simultaneously supplying liquidity through refinancing operations (i.e., by auctioning reserves balances in return for collateral in weekly (one-week term) main refinancing operations (MROs) and mid-maintenance-period (3 month term) longerterm refinancing operations (LTROs)). In essence, transfers of reserves among banks enable payments of bank customers to be made more efficiently. The rate of return on reserves is determined by the weighted average rate at which refinancing operations were settled in a previous maintenance period and this normally tracks the ECB's target interest rate very closely. Banks can use interbank transactions to top-up (or share) their reserves and they can also manage their reserves by accessing liquidity made available through the ECB's 
refinancing operations.

Since reserve requirements must only be met on average (over approximately monthly reserve maintenance periods), banks have a significant degree of flexibility in allowing reserves to temporarily deviate from required levels. ${ }^{2}$ This facilitates substitution of the sourcing of liquidity across time as well as across alternative sources. This flexibility, of course, diminishes as the end of each maintenance period approaches and banks usually spread their reserve management unevenly over the maintenance period to guard against breaching their requirements when it is expected to be most expensive. Addressing this maintenance period timing effect is, in our view, worthwhile. It sharpens test statistics so that the causal structure can be better understood. We control for within, and across, maintenance period effects through the use of additive and multiplicative dummy variables. We also control for much more pronounced seasonal effects at the end of the year.

Even with adequate controls for maintenance period effects there are fundamental challenges involved in assessing how interbank and official funding sources relate to each other. For example, in the pre-crisis period there was a non-stationary pattern to trading activity in the interbank market while at the same time nearly all aspects of auction outcomes were stationary. We therefore model the relationship between 'repo roll-over' innovations (i.e., the excess or shortfall in new repo transaction value as a percentage of the value of maturing repos) and auction outcomes for this period. Repo roll-over innovations are shown to affect outcomes of auctions and to be related to previous auction outcomes. An event analysis also shows that cumulative roll-over innovations are related to the ECB's interest rate setting from late 2005 to June 2007 with roll-over excesses increasing before interest rate increases and then declining sharply afterward.

The crisis introduced a number of complications to assessing the relationship between interbank and official funding sources due to the frequency and size of structural shocks that occurred. The structural changes are eventually shared by the two funding venues but it is plausible (or very probable) that they originate in the interbank market as idiosyncratic effects. The contrasting time series properties of the two principal endogenous variables does not rule out meaningful interactions but it limits the nature of the causal relation we can uncover empirically. Therefore, for the crisis period we propose a semi-structural

\footnotetext{
${ }^{2}$ Until recently, reserves were required to be $2 \%$ of short term liabilities reported two months prior to the beginning of a given reserve maintenance period. In December 2011 this requirement was halved to $1 \%$.
} 
model that identifies cross-venue effects that can be identified as primarily due to auction outcomes.

\section{Model and Econometric Approach}

In the pre-crisis period it is plausible to assert that $P^{a u c}$ is a stationary series. This is true when we test the series for stationarity (before the financial crisis) and it is consistent with priors based on the structure of the auction setup. Auctions during this period involved a planned allotment based largely on maturing amounts from previous auctions and this intended allotment was announced to participants in advance of auctions and generally adhered to. While the quantity allotted was approximately fixed, it is also the case that the settlement rate was quite stable. Auction bids appear to have been influenced by a belief that the settlement rate would closely track the targeted interest rate on reserves (a rational belief on the part of banks given the announcement of a credible policy target). While it is likely that the repo rate prevailing in the interbank market also tracked the intended auction rate, we find that interbank market activity is non-stationary and we therefore examine the roll-over of maturing repos during the pre-crisis period. We analyze the pre-crisis interaction using a modified VAR model.

In contrast to the stability of the deviation of the weighted average settlement rate, $P^{a u c}$, from its target during the pre-crisis period, $P^{a u c}$ becomes non-stationary during the crisis (specifically in the crisis period previous to the Lehman collapse). This seems to reflect the increasing willingness of the ECB to adjust the settlement rate as well as the allotment quantity in response to the persistent innovations in the aggressiveness of bidding behaviour by banks that found themselves locked out of the interbank market. In this regime there are potentially multiple stochastic trends in the $P^{a u c}$ series (i.e., the accumulated effects of shocks to the liquidity needs of banks excluded from the interbank market, changes in beliefs about how closely the auction settlement rate would adhere to the target interest rate and innovations in the ECB's auction policy stance). Trivially, in the post-Lehman period the ECB introduced fixed-rate full-allotment auctions so that $P^{a u c}$ is fixed in this period. Quantity allotted becomes of interest in this period and we model it as a cause of (and function of) interbank activity.

$Q^{r e p o}$ is non-stationary in all the periods we study but there are probably different 
reasons for this depending on the regime. There are two competing stories for this nonstationarity in the pre-crisis period. One concerns developments in the repo market while the other involves loose monetary policy. Innovations in the network efficiencies of the market as well as innovations in drivers of repo activity related to macroeconomic and financial developments could certainly matter for the efficiency with which any stock of reserves can be leveraged. There is ample anecdotal evidence that random innovations in the efficiency of securities lending facilitated permanent changes in repo-related leveraged speculation and shorting. Efficiency gains in the trading of repos and in the underlying collateral used in repos can also be attributed to the introduction of electronic trading platforms and better settlement mechanisms. Occasionally there were also innovations in how counterparty risk was managed through margin mechanisms. ${ }^{3}$

All of these developments seem plausible explanations for the non-stationarity of activity. However, during this period (after the dot-com crash and up-until November 2005) there was a persistently low official interest rate, with limited inflation concerns, and this loose policy stance may have contributed to a weakening of the intended constraints on interbank activity and a growing disconnect between auction outcomes and interbank activity. ${ }^{4}$ With auction allotment becoming an ever smaller proportion of growing interbank activity it is tempting to regard monetary policy operational levers as progressively less relevant over time. Using the pre-crisis VAR model as a baseline for the expected relation between the interbank sharing of liquidity and the aggression of bidding in ECB auctions provides us an opportunity to conduct an event analysis for a series of interest rate changes that took place from November 2005 to the beginning of the crisis. This sheds light on the question as to whether monetary policy had lost its effectiveness due to other (liquidity sharing) efficiency developments.

Repo volume is non-stationary during the crisis period for quite different reasons (being constantly affected by crisis events and the policy responses). These effects include shocks

\footnotetext{
${ }^{3}$ In addition to these structural changes, other potential sources of non-stationarity arise from using the trading activity from a single trading platform because of movements of activity across venues and between unsecured and secured activity. This adds to the need for an analysis of repo roll-over activity in order to reveal the higher frequency relationship more precisely.

${ }^{4}$ There may also be some significance in the fact that the role of money was de-emphasized by the ECB in its May 2003 statement on monetary policy strategy after which we observe a general rise in repo market activiy (see, Berger, de Haan and Sturm 2011 for a discussion and analysis of this change).
} 
to collateral quality, collateral and liquidity hoarding, shocks to counterparty risk and to uncertainty about where such risks were located. In addition, it is plausible that ECB auction policy (including innovations in the repo rate, auction term and allotment amounts) and changes in the aggressiveness of bidding in auctions, affected the amount of interbank trading that was required to achieve reserve requirements. And since banks were restructuring their balance sheets, there were continual structural changes in the required level of reserves. Clearly, some aspects of the crisis-related stochastic trends become common to auction outcomes and interbank market activity, but some remain idiosyncratic to the interbank market (including extraordinary liquidity assistance, ELA, and banks' balance sheet shrinkage exercises). This structure motivates a structural model that contributes to improved interpretation of a VARMA empirical model.

\subsection{Pre-Crisis VAR Model}

Granger causality is typically assessed by applying a vector auto regression to the jointly observed series and then by the application of block-exogeneity tests. We adopt this modeling approach for the pre-crisis relationship between interbank trading volume (or roll-over), $Q^{r e p o}$ and the excess weighted average settlement rate obtained in auctions, $P^{a u c}$. However, a VAR structure is not straightforward to apply in this case because there is likely to be a significant difference in effects that occur within a maintenance period (MP) and those that cross-over from one maintenance period to the next. MP-seasonality is also very irregular so that autoregressive coefficients would relate to variable timings within previous maintenance periods (within the pre-crisis sample there are maintenance periods with as few as three MRO auctions while others have six). In addition, auctions are not occurring simultaneously with interbank activity (they occur at the end of a period of interbank sharing of liquidity). So information is lost in a standard VAR setup if only lags are included on the RHS. We therefore employ a modified VAR approach in which there is a separation between the within- and cross-MP effects.

The modified near-VAR model that we use for the pre-crisis period is as follows (where, more exactly, $P^{a u c}$ is the deviation of the weighted average settlement rate in auctions in excess of the ECB's minimum lending rate and $Q^{\text {repo }}$ is the daily average percentage excess 
or shortfall in interbank roll-over of maturing repos for days between ECB auctions $)^{5}$;

$$
\begin{gathered}
{\left[\begin{array}{c}
P_{t}^{\text {auc }} \\
Q_{t}^{\text {repo }}
\end{array}\right]=\left[\begin{array}{l}
\boldsymbol{a}_{0,01} \\
\boldsymbol{a}_{0,02}
\end{array}\right] \boldsymbol{d}_{0}+\left[\begin{array}{cc}
0 & \boldsymbol{a}_{1,12} \\
0 & 0
\end{array}\right] \boldsymbol{d}_{1}\left[\begin{array}{c}
P_{t}^{\text {auc }} \\
Q_{t}^{\text {repo }}
\end{array}\right]+} \\
{\left[\begin{array}{cc}
\boldsymbol{a}_{2,11} & \boldsymbol{a}_{2,12} \\
\boldsymbol{a}_{2,21} & \boldsymbol{a}_{2,22}
\end{array}\right] \boldsymbol{d}_{2}\left[\begin{array}{c}
P_{t-1}^{\text {auc }} \\
Q_{t-1}^{\text {repo }}
\end{array}\right]+\cdots+\left[\begin{array}{c}
\epsilon_{t} \\
\eta_{t}
\end{array}\right]}
\end{gathered}
$$

In this near-VAR the $\boldsymbol{d}_{i}$ are vectors of $\{0,1\}$ dummy variables with the following meanings:

- $L A S T_{t}=1$ if the auction at the end of period ' $t$ ' is the last of the maintenance period.

- $E O Y_{t}=1$ if the auction at ' $t$ ' is around the end of the year (specifically, one of the first or last two auctions of the year).

- EOY $A=1$ for the last two auctions of the year.

- $E O Y B=1$ for the first two auctions of the year.

- WITHIN = 1 if the current dependent variable and the lagged (or current) explanatory variable are within the same maintenance period.

- $A C R O S S=1$ if the current dependent variable and lagged explanatory variable are in different maintenance periods.

- $L T R=1$ if the auction in period 't' is an LTRO auction.

- $L T R L=1$ if the auction in period 't-L' is an LTRO auction. This allows for a different relationship when MRO auction outcomes are being related to LTRO outcomes ' $L$ ' periods previous.

The dummy variable vectors are as follows (with no need for an "ACROSS" maintenance period dummy in the contemporaneous case);

$$
\boldsymbol{d}_{0}=\left[\begin{array}{c}
W I T H I N_{0, t} \\
L A S T_{0, t} \\
E O Y A_{0, t} \\
E O Y B_{0, t} \\
L T R_{0, t}
\end{array}\right], \boldsymbol{d}_{1}=\left[\begin{array}{c}
W I T H I N_{1, t} \\
L A S T_{1, t} \\
E O Y_{1, t} \\
L T R_{1, t}
\end{array}\right] \text { and for } i>1 \boldsymbol{d}_{i},=\left[\begin{array}{c}
W I T H I N_{i, t} \\
A C R O S S_{i, t} \\
L A S T_{i, t} \\
E O Y_{i, t} \\
L T R_{i, t} \\
L T R L_{i, t}
\end{array}\right]
$$

\footnotetext{
${ }^{5}$ Modeling the conditional variance in a fully specified maximum likelihood estimation of this model initially seemed worthwhile but we found no statistical support for the presence of ARCH effects once turn-of-year seasonality was controlled for.
} 
The $\boldsymbol{a}_{i, j k}$ are row vectors. The case of $\boldsymbol{a}_{1, j k} \boldsymbol{d}_{1}$ is therefore as follows;

$$
\left(\begin{array}{c}
a_{1,11} \\
a_{1,12} \\
a_{1,21} \\
a_{1,22}
\end{array}\right)=\left(\begin{array}{c}
a_{1,11,1}, a_{1,11,2}, a_{1,11,3}, a_{1,11,4}, a_{1,11,5}, a_{1,11,6} \\
a_{1,12,1}, a_{1,12,2}, a_{1,12,3}, a_{1,12,4}, a_{1,12,5}, a_{1,12,6} \\
a_{1,21,1}, a_{1,21,2}, a_{1,21,3}, a_{1,21,4}, a_{1,21,5}, a_{1,21,6} \\
a_{1,22,1}, a_{1,22,2}, a_{1,22,3}, a_{1,22,4}, a_{1,22,5}, a_{1,22,6}
\end{array}\right)\left(\begin{array}{c}
\text { WITHIN }_{t} \\
\text { ACROSS }_{t} \\
\text { Last }_{t} \\
\text { EOY }_{t} \\
\text { LTRt }_{t} \\
\text { LTRL }_{t}
\end{array}\right) .
$$

There are enough observations in the pre-crisis period to estimate this expanded model so long as the number of lags remains small. We only consider models with three autoregressive lags. Note that most of the dummy variables have to be tailored for each specific lag (so, for example, the "within" dummy will include fewer ones as the lag length increases). ${ }^{6}$ We test exogeneity restrictions in the usual way by testing the joint significance of groups of parameters (we start by restricting the 'across' parameters to be zero before moving to test exclusion of the 'within' parameters).

In addition to causality analysis, we use the residuals from the above model to assess the effects of interest rate changes (these are all positive innovations in the targeted interest rate in the two years preceding the crisis). ${ }^{7}$ The unexpected auction outcomes and roll-over of interbank repos in the five operations before and after an interest rate move are accumulated to assess the effect of these moves. This allows us to ascertain whether monetary policy has the expected effects on collateralised short-term credit creation. A contractionary policy should lead to less repo roll-over and perhaps increased bidding aggressiveness at official auctions. However, such changes should take place over an extended period of time (since monetary policy innovations are expected to have real effects with long and variable lags). We find that the interest rate rises caused very significant and sudden contractions in repo roll-over. This would be consistent with a less benign form of causality running from monetary policy to mortgage asset impairments to counterparty risk and ultimately

\footnotetext{
${ }^{6}$ For the case of the $\mathrm{AR}(1)$ parameters, for example, an interactive dummy variable is multiplied by the RHS variables that are subscripted with $t-1$ which is 1 in period $t$ if the auction in period $t$ is not the first auction of the maintenance period and zero otherwise. An orthogonal dummy is included to capture the case where the auction in period $t$ is the first auction and this is also multiplied by the variables subscripted with $t-1$. Similarly, for any $q>0$ there will be an interactive dummy (and its orthogonal counterpart) multiplied by the $\operatorname{AR}(\mathrm{q})$ parameter which is 1 if the auction at time t occurs later than the $q^{\text {th }}$ auction of the maintenance period and zero otherwise. There is obviously no need for 'WITHIN', 'ACROSS' and 'LTRL' in the case of $\boldsymbol{d}_{1}$ because variables are being compared within the same period in this case.

${ }^{7}$ There were eight ECB interest rate increases between November 2005 and May 2007.
} 
shrinkage in interbank market activity. It also prompts discussion of the likely cause of the rise in repo volume during the early pre-crisis period. While it is plausible to suggest that repo volume rose because of improvements in repo trading network efficiencies (and collateral lending), these improvements continued into the late pre-crisis period and were still easily counteracted by interest rate increases. It seems that technology was facilitating the response of repo volume to loose policy earlier in the sample rather than overwhelming policy effectiveness.

\subsection{Crisis-Period Modelling}

A VAR approach could be applied to assess interactions in the crisis regimes but we appeal to a different specification that more effectively isolates the effects of innovations in auction behaviour (and allotment policy) on interbank market activity. Since our focus is on how the auction innovations feedback on the interbank market there is some advantage from directly isolating these innovations. This model is more relevant for the first crisis regime but we will apply it to both regimes showing that causality breaks down once fixed-rate full-allotment auctions are introduced. The model can be identified with fewer parameters than a VAR and it helps with interpretation of the types of feedback that come from auction behaviour and policy changes. The associated empirical strategy (which is approximately a VARMA representation) is based directly on this plausible structural interpretation of the interactions between repo market crisis effects and auction policy responses (inclusive of innovations in auction bidding behaviour). We ignore interactive MP-seasonality in the crisis period since these are small relative to crisis effects but we retain end of year effects.

It is worthwhile considering in some detail how observed and unobserved effects can be identified in an empirical representation of auction and repo market interactions during the first crisis regime. We observe the outcomes from auctions (specifically, allotment innovations and bidding aggressiveness in the form of a larger spread between the weighted average settlement rate and the policy target) and from interbank activity (i.e., the extent

of the sharing of liquidity and collateral through trading) as well as variables indicating changes in counterparty quality, risk aversion, hoarding of liquidity and collateral, and changes in collateral quality (i.e., bank and sovereign CDS spreads and microstructure variables such as bid-ask spread and depth of the limit order book from the repo market). However, the auction and interbank variables are jointly determined and have a 
complex dynamic relation with each other. The history of past innovations in auction allotment, bidding behaviour and interbank market dislocations are accumulated such that each observed variable is a mixture of effects. The settlement rate and trading activity are endogeneous but we assume that, for the frequency of our analysis, the previously observed CDS spreads and the microstructure indicators can be considered as exogenous.

In the present context it is possible to directly assess the effects of the auction-related structural innovations on interbank repo activity by including a lagged residual from the auction equation in the repo equation. The structural model we now outline gives rise to a partial VARMA specification that is an alternative to the VAR empirical approach and enables a more direct and tractable assessment of auction effects on interbank market activity under the constraints just described. It is also restrictive enough to avoid identification issues often associated with generalized VARMA modeling (see, for example, Lütkepohl, 2005).

We assume that auction price and quantity $\left(P^{a u c}\right.$ and/or $\left.Q^{a u c}\right)$ respond to developments in the interbank market - which we represent as $Q^{a u c}$. The cumulative response can be represented by a random walk, $W_{t}=W_{t-1}+\omega_{t}$, which is common to the auction and interbank variables. These common effects come from the substitutability of locating reserves in the two venues. A relatively high price in auctions will usually cause a rise in the quantity conducted in the interbank market (controlling for other effects). A higher supply at auctions will usually involve reduced need for interbank activity. These effects are assumed to be approximated by a random walk during the first crisis regime because they involved some accumulation of unpredictable innovations in the auctioneer's trade-off between allowing the weighted average settlement rate to diverge from the policy target and maintaining the supply of reserves close to the perceived reserve requirement of the banking system.

We assume that the interbank market is the location where crisis effects enter the reserve management and sharing system. Crisis effects are assumed to be related to counterparty and credit risk developments as well as a range of other occurrences (e.g., direct state funding through ELA or asset and liability shrinkage exercises by banks) and we denote these as a random walk process $Z_{t}=Z_{t-1}+\zeta_{t}$. We will define this component in such a way that positive innovations represent an improvement in risk - and other structural conditions - so that $Z_{t}$ enters with a positive sign in the interbank market equation (ceteris 
paribus). The interbank market is also affected by past auction allotment policy and bidding behaviour (the sign on this will depend on whether we are referring to the $P^{a u c}$ or $Q^{a u c}$ variable). The interbank market can be written as follows (where $\eta_{t}$ is an additional noise term);

$$
\begin{aligned}
Q_{t}^{\text {repo }}=b_{0} & +b_{1} W_{t-1}+Z_{t}+\eta_{t} \\
\text { where... } W_{t} & =W_{t-1}+\omega_{t} \\
Z_{t} & =Z_{t-1}+\zeta_{t} \\
\omega_{t} & \sim i i d\left(0, \sigma_{\omega}^{2}\right) \\
\zeta_{t} & \sim i i d\left(0, \sigma_{\zeta}^{2}\right) \\
\eta_{t} & \sim i i d\left(0, \sigma_{\eta}^{2}\right)
\end{aligned}
$$

Consider now the auction equations (for convenience we depict the case of the weighted average settlement rate, $P^{a u c}$, but the case of $Q^{a u c}$ is analogous). The auction can be described as having components related to the cumulative auction allotment policy changes (and cumulative changes in bidding behaviour) as well as the accumulated feedback that previous auctions had on the interbank market. The auction equation is therefore as follows (where $\mu_{t}$ is an additional noise term);

$$
\begin{aligned}
& \qquad P_{t}^{a u c}=a_{0}+W_{t}-a_{1}\left(b_{1} W_{t-1}+Z_{t}+\eta_{t}\right)+\mu_{t} \\
& \text { where... } \mu_{t} \sim \operatorname{iid}\left(0, \sigma_{\mu}^{2}\right)
\end{aligned}
$$

Substitution of the interbank market activity variable, $Q^{\text {repo }}$, into the auction equation will result in the following;

$$
P_{t}^{a u c}=a_{0}+W_{t}-a_{1} Q_{t}^{a u c}+\mu_{t}
$$

If $Z_{t}$ was observable we could subtract it directly from the auction equation and the model would be fully identified and a separation of the auction contribution to the interbank 
market could be measured. Since $Z_{t}$ is a permanent component it could be estimated by calculating the long run effect of idiosyncratic random walk shocks in the interbank equation as described in Beveridge and Nelson(1982). However, this also requires that $W_{t-1}$ is identified in the interbank equation. Since this is not directly possible we consider a different approach to identifying the components. Differencing the terms in both equations results in the following model (where we use dot notation to indicate a differenced variable or, more specifically, either the percentage roll-over relative to maturing repos or the excess or shortfall in allotment relative to amounts from maturing operations).

$$
\begin{aligned}
\text { Auction difference equation: } \dot{P}_{t}^{a u c}= & \dot{W}_{t}-a_{1} \dot{Q}_{t}^{\text {repo }} \\
& +\mu_{t}-\mu_{t-1} \\
\text { Interbank difference equation: } \dot{Q}_{t}^{r e p o}= & b_{1} \dot{W}_{t-1}+\dot{Z}_{t}+\eta_{t}-\eta_{t-1} .
\end{aligned}
$$

Further simplification results in the following;

$$
\begin{aligned}
\text { Auction difference equation: } \dot{P}_{t}^{a u c}= & -a_{1} \dot{Q}_{t}^{r e p o}+\omega_{t} \\
& +\mu_{t}-\mu_{t-1} \\
\text { Interbank difference equation: } \dot{Q}_{t}^{r e p o}= & b_{1} \omega_{t-1}+\zeta_{t}+\eta_{t}-\eta_{t-1} .
\end{aligned}
$$

One useful outcome from these manipulations is that it shows that the auction equation can be estimated with an MA(1) error process $e_{t}+\phi e_{t-1} \approx \omega_{t}+\mu_{t}-\mu_{t-1}$. We note that $\omega_{t}$ is a prominent component of this error process but unfortunately it is combined with a noise term (there is also a possibility that $\omega_{t}$ is correlated with $\zeta_{t}$ but we leave examination of this until a robustness analysis is done). The interbank market equation can also be represented as an MA(1) which features the lagged auction innovation $\omega_{t-1}$. It would be useful if a measure of $\omega_{t-1}$ was available to include separately in this equation. We therefore consider whether the error $e_{t-1}$ from the auction equation, which is likely to be highly correlated with $\omega_{t-1}$, could be used to good effect in the repo market equation when it is combined with other variables that capture developments in the interbank market. Suppose we have variables, denoted $h_{t}$, that capture innovations in banks' counterparty risk, changes in 
collateral quality and/or other measures of changes in the efficiency with which interbank borrowing and lending can be achieved. These variables are likely to be correlated with $\zeta_{t}$ and $\eta_{t}$ and uncorrelated with $\omega_{t}$ (we assume that the monetary policy auctioneer is not monitoring the interbank market and responds with a lag to developments there this seems to be a good description of what was happening during this part of the crisis according to the presence of surprise bidding aggressiveness in the auctions as described by Drehmann and Nikolau 2009). These variables could therefore be used to control for interbank idiosyncratic effects in the following empirical model;

$\begin{aligned} \text { Auction difference equation: } \dot{P}_{t}^{a u c} & =-\hat{a}_{1} \dot{Q}_{t}^{r e p o}+e_{t}+\phi e_{t-1} \\ \text { Interbank difference equation: } \dot{Q}_{t}^{r e p o} & =\hat{b}_{1} e_{t-1}+\hat{b}_{2} h_{t}+v_{t}+\pi v_{t-1} .\end{aligned}$

The coefficient on the lagged auction equation residual $\hat{b}_{1}$ should therefore represent the contribution of $\omega_{t-1}$ to stabilizing or harming the sharing of funding in the interbank market. We can test this parameter for statistical significance in order to test whether there is a role for allotment policy and auction bidding behaviour in affecting the interbank market. The inclusion of $h_{t}$ should lead to a reduction in the significance of the MA(1) coefficient in the interbank equation. This can be used as a test of whether the controls are effective. The improvement in the fit of the interbank equation when the lagged residuals from the auction equation are added provides a measure of the size of the contribution from auction effects on interbank activity.

The steps of this empirical strategy can be summarized as follows;

1. Regress $\dot{Q}^{a u c}$ (and do the same for $\dot{P}^{a u c}$ in the Variable Rate Auction crisis period) on $\dot{Q}^{\text {repo }}$ and include MA terms.

2. Collect the lagged residuals from this (or each of these) model(s).

3. Regress $\dot{Q}^{r e p o}$ on the lagged collected residuals and include MA terms.

4. Test the significance of the added residuals. This is potential evidence of the presence of an auction effect. The sign of this effect will reveal whether price or quantity effects 
are stronger (it seems more likely that there would be a negative parameter on the quantity equation residuals).

5. Test the joint significance of any included MA terms. If these are significant this is interpreted as evidence of the presence of endogenous effects in the added residuals.

6. Add controls for changes in counterparty risk, collateral quality and interbank market microstructure indicators to the regression of step 3.

7. Test for significance of the added controls. Significance signifies that endogeneity has been controlled for (although this, on its own, is not sufficient for such a conclusion).

8. Test for significance of the MA terms. If MA terms become insignificant when the controls are added this provides further evidence that endogeneity has been almost surely controlled for.

9. Re-test for significance of the added residuals. If they remain significant while controls are significant and MA terms are insignificant then this is interpreted as strong evidence of an auction effect.

In the case of the first crisis period both the settlement rate, $P^{a u c}$, and the quantity allotted, $Q^{a u c}$, are relevant indicators of auction policy and behaviour. We therefore run these two regressions separately and we use the lagged residuals from both auction regressions in the interbank regression. In this way we can ascertain whether increased overall allotment quantity or the more targeted allocation of auction funding due to bidding aggressiveness was most important in affecting the interbank market. In the second crisis period (when fixed-rate full allotment applies) we revert to just one auction regression which concerns auction allotment, $Q^{a u c}$.

We estimate the above model using various candidates for the set $\left\{h_{t}\right\}$, such as indexes of country-specific bank CDS spreads (specifically $\log (\mathrm{CDS})$ ), sovereign debt CDS spreads, the Euribor-OIS spread and microstructure variables from the interbank market such as innovations in bid-ask spreads and changes in market depth. In the second crisis period there is less reliable data for CDS spreads and we therefore rely on repo market microstructure variables alone. 


\section{ECB Auction \& Interbank Repo Data}

\subsection{ECB Auction Data}

Until October 2008 all ECB operations were done by way of competitive auctions in which a planned quantity of liquidity was allocated firstly to the best bidder(s) and then to progressively lower bids until all the planned (and announced) allotment amount was exhausted (on a discriminating price auction basis). Monetary policy operations during the crisis involved a number of very different approaches by the ECB to mitigate the effects of the financial turmoil. In the pre-Lehman crisis phase, the ECB modified its funding procedures by (1) adjusting the distribution of liquidity over the reserve maintenance period by systematically allotting liquidity in excess of the 'benchmark allotment' (this was front-loaded near the early part of the maintenance period) while still aiming for balanced liquidity conditions at the end of the maintenance periods, (2) extending the average maturity of its financing by use of Supplementary LTROs (SLTROs), and (3), engaging with other central banks to relieve liquidity shortages of Euro Area banks in other currencies (mostly US dollars as extensions of the TAF operations).

When crisis-related stresses within the interbank market were escalated by Lehman's failure, in addition to aggressive reductions in the targeted refinancing rate, the ECB (1), introduced a fixed rate tender procedure with full allotment in both the main refinancing operations and the long-term refinancing operations, (2) increased the number of longer term operations ${ }^{8},(3)$ increased the range of assets eligible for use as collateral in Eurosystem credit operations ${ }^{9}$ and (4) increased US dollar swap financing by use of fixed-rate tenders with full allotment by special arrangements with the Federal Reserve System.

In the period from 2010 policy became even more accommodating in the context of the sovereign debt crises that occurred in peripheral Euro Area countries. This led to further relaxations in the type and quality of collateral that could be used in official operations ${ }^{10}$,

\footnotetext{
${ }^{8}$ The ECB introduced three additional operations per month (two with a three month term and one with a six month term) and an additional operation with a term corresponding to the reserve maintenance period.

${ }^{9}$ The list of eligible collateral was expanded on 15th October 2008 and in May 2009 this policy was prolonged until the end of 2010 .

${ }^{10}$ Some widening of the type of acceptable collateral was initially combined with restrictions on quality. Quality restrictions were imposed on asset backed security collateral in November 2009. There was a
} 
various asset market intervention programmes (including two Covered Bond Purchase Programmes and the Securities Markets Programme), extension of fixed-rate full-allotment auctions, introduction of a number of supplementary long-term operations (including the three year operations announced at the end of 2011) and a halving of the required reserves ratio to $1 \%$ of applicable liabilities in December 2011.

These changes are largely visible in sovereign yield spreads and to some extent in measures of counterparty risk. The speech by Mario Draghi in London in July 2012 made a commitment to defend against a euro break-up that was perceived as contributing to the excessive elevation of peripheral sovereign bond yield spreads. Soon after the speech the OMT (Outright Monetary Transactions) programme was announced and, although the policy was not implemented, the demonstration of policy resolve had a persistent calming effect on markets and reduced sovereign yield spreads through the end of our sample period. It is also possible that the acceptance of poorer quality collateral in ECB operations led to improved quality of collateral among a smaller group of relatively high-quality banks within the interbank market. These effects are difficult to untangle and since we only have access to interbank repos based on sovereign collateral we concentrate on CDS spreads (sovereign and banking sector) as the main harbingers of counterparty and collateral quality developments and we leave more detailed collateral analysis for future work.

The auction data used in our analysis is available on the ECB's website. There are a range of auction outcomes that are reported soon after auctions take place. The most relevant variables for our analysis relate to the settlement rate and the quantity allotted. Many of the other auction variables are correlated with these (e.g., unsatisfied demand and number of bidding banks). We therefore focus on the rate and/or quantity outcomes from auctions depending on the sample studied.

\subsubsection{The Auction Settlement Rate}

There are two settlement rates that are reported after auctions. One is the marginal rate and the other is the weighted average rate. The marginal rate is the lowest rate at

relaxation in the quality of acceptable sovereign collateral when Greek bonds were declared acceptable despite a reduced credit rating in May 2010 and this was extended to Irish sovereign collateral in March 2011 and to Portuguese collateral in July 2011. Collateral rules were eased further in December 2011, see http://www.ecb.int/press/pr/date/2011/html/pr111208_1.en.html for details. 
which auction allocation is exhausted. The weighted average rate is the weighted sum of all the bid rates at which allocations are made where weights are the proportion of total allocation that is made at each bid rate. These two price outcomes are positively correlated but the weighted average rate tends to be more variable and, in our view, contains more information about the aggressiveness of bidding in auctions. We therefore use the weighted average rate as the basis for the auction rate variable in our regression analysis. Since this rate is non-stationary in the first crisis period, we transform it by taking the percentage change in the weighted average rate relative to the rate charged by the ECB on its marginal lending facility (this closely tracks the ECB target rate but it is usually around 1 whole percentage point above the target rate). Figure 1 shows a plot of the excess weighted average settlement rate and its change relative to the lending rate.

The deviation of the weighted average settlement rate from the ECB's target marginal rate widens at points of acute stress during the early part of the crisis and is at its maximum around the Lehman event. This is indicative of the level of banks' aversion to liquidity shortfalls and also of the reluctance of the ECB to provide funding in excess of what was planned. It is known that during the variable rate auction phase of the crisis, some participants were more desperate to ensure allocation at auctions and submitted bids at much higher rates than the target marginal rate (this is described in Drehmann et al., 2009). ${ }^{11}$

\subsubsection{Auction Supply \& Outstanding Liquidity}

In normal times, the amount allotted through ECB auctions is very similar to the amount maturing from a previous auction. However, during the pre-Lehman crisis period there was a degree of flexibility in allotment quantity and this is of interest in our analysis. Also, during the post-Lehman period there was a fixed rate and a completely variable allotment quantity. We therefore construct an auction supply shock variable that is based on the difference between allotment and the amount maturing from a similar previous auction

\footnotetext{
${ }^{11}$ Drehmann, Eisenschmidt and Nikolaou (2010, 3013) use the aggressiveness of bidding behaviour of banks in Main Refinancing Operations (MROs) as an indication of their "funding liquidity risk aversion." The deviation between the intended policy target rate and the weighted average rate obtained by participants in official operations is a close substitute for their measure and is indicative of variation in liquidity needs not satisfied in the interbank market.
} 
(i.e., a percentage excess relative to amounts maturing). These level and innovations series are shown in Figure 2.

In the pre-crisis period, refinancing operations of the ECB were very stable with around 300 billion euro outstanding in weekly refinancing of liquidity provision on an on-going basis. The supply in MRO auctions was roughly equal to what was maturing from the previous week's operation. Likewise, in the pre-turbulence period, allotment and demand at LTRO was stable and usually involved outstanding repo lending by the ECB of about 100 billion euro (also planned to replace maturing operations). In the last quarter of 2008 allotment in MROs declined to achieve about 150 billion euro outstanding and this facilitated an increase in the supplementary longer term operations (SLTROs). SLTROs were of increasingly longer duration and new supply in these operations was more than replacing what was maturing from previous operations.

The two 3-year operations conducted at the end of 2011 and early 2012 pushed the outstanding liquidity supplied through MRO and LTRO operations to almost 1.4 trillion euro. The outstanding liquidity associated with LTRO and MRO operations is shown in Figure 3. The introduction of the 3 year operations was a major break with normal operations in terms of supply. These increases were to a significant extent matched by increases in the amounts deposited with the ECB. This indicates a precautionary motive for accessing ECB liquidity at the longer term operations in order to fund possible future demand shocks.

\subsection{Euro-Area Interbank Repo Markets \& Repo Data}

The European Repo Council's (ICMA) biannual survey of European repo trading reveals that traded repo volume grew at a rate of roughly 20\% each year between June 2001 and June 2007, reaching a high point of 6,504 bln EUR in June 2007. ${ }^{12}$ It declined to 4,633 bln EUR in December 2008 after the financial crisis hit before recovering to 6,885 bln EUR in June 2010; it then declined again to 5,611 bln in December 2012. Almost $60 \%$ of repos

\footnotetext{
${ }^{12}$ The interbank repo market in Europe is surveyed on a semi-annual basis by the European Repo Council of the International Capital Market Association (ICMA). The survey provides a snapshot of the volume of repo trades outstanding on a single day in June and December each year and various other indicators of the market structure and growth. The latest survey is posted here:http://www.icmagroup.org/ Regulatory-Policy-and-Market-Practice/short-term-markets/Repo-Markets/repo/latest/
} 
declared in the ICMA survey are based on euro denominated government bonds but the survey notes indicate that there is a degree of double counting of this volume (about $20 \%$ of trades are likely repeated records in the case of repos using Euro Area sovereign collateral).

\subsubsection{Interbank Repo Market Data}

Our analysis is based on the volume of repos traded on the BrokerTec Inter-Dealer Trading Platform using Euro Area sovereign collateral. We use the daily average of volume over the days between auctions. Activity on BrokerTec's repo trading platform in sovereign backed repos largely reflects a similar pattern to the ICMA survey of all Euro Area repo volume over time. ${ }^{13}$ We estimate that BrokerTec accounts for up to $17 \%$ of all trading in repos using Euro Area sovereigns and approximately $50 \%$ of the automated trading system (ATS) traded volume of such repos. ${ }^{14}$

Figure 4 displays the time series of ICMA reported volume and the daily volume traded on BrokerTec. Both series display a secular increase throughout the pre-crisis period. There is a high degree of consistency between BrokerTec volume and the overall volume of activity in repo markets revealed in the ICMA survey results. Between the start of the interbank market disruptions of 2007 and the Lehman collapse in October 2008 there was a sharp downward trend in daily volume traded on BrokerTec (falling from 350 bln to about 250 bln). Soon after the Lehman collapse there was an increase in activity for a while and, apart from some significant temporary declines around the times of the Greek and Irish sovereign debt crises, there was a general improvement in activity up until late summer 2011 when there was significant contagion to Spanish, Portuguese and Italian sovereign debt markets. Mid-way through the second quarter of 2012, BrokerTec trading activity had returned to its pre-crisis highs of about 400 bln in daily volume. Activity declined again during the euro (break-up) crisis of the summer of 2012 until (ECB president) Mario Draghi's comments reversed sentiment in late July. Activity has remained high on average since then but with increased variability.

\footnotetext{
${ }^{13}$ Trading in Italian repos is mostly conducted on the MTS platform. The other venue that has a significant share of repo trading is the Eurex exchange and the characteristics of this repo activity is studied in detail by Mancini, Ranaldo and Wramplemeyer (2013).

${ }^{14}$ The combined volume of repo activity conducted on BrokerTec and MTS is available at http://www . repofundsrate.com/.
} 
The volume traded is interesting in itself, but for the purposes of our analysis we use the average daily volume traded in excess of volume maturing (as a percentage of amount maturing) based on all previous repos traded on the BrokerTec platform. The constructed series is shown in Figure 5. This behaves like a first difference of the total volume traded but this construct avoids introducing complex moving average dynamics due to variation in the maturity of the previous day's trades. To make this data transformation it is necessary to track the maturing trades from the past. Fortunately, the trade-by-trade data supplied by ICAP includes the term of contracts so this transformation of the data is possible with limited error. To account for the fact that some trades that mature early in the sample are not observable because they were contracted before the start of our sample, we use the first six months of the sample to generate the first data point used in the analysis. We use a comprehensive set of sovereign repo contracts in our analysis. The data supplied by ICAP covers a wide range of specific and general repo contracts associated with collateral issued by almost all Euro Area sovereigns and for various terms to maturity. A relatively large proportion of all activity on BrokerTec is associated with repo contracts that use named collateral but these are done at rates that differ only slightly from general collateral rates and we therefore include them in our analysis.

The depth and spread control variables used in the regression analysis below are based on the series displayed in Figure 6 and Figure 7. These variables were measured for

each individual market by repo collateral and term. The daily time weighted averages of individual contracts were averaged across the contracts associated with country-specific collateral to get the relevant country measure.

\subsubsection{Sovereign and Bank CDS Data}

The CDS spread variables were obtained from a Bloomberg source of Markit data. All available bank-specific CDS contracts, for the main banks within each country included in our analysis, that insures credit default on senior bonds at a 5 year maturity were collected at the end of each trading day. CDS premiums on sovereign bonds of 5 year maturity were similarly collated. Country-level bank CDS indexes were calculated as a simple average of the bank-specific CDS premiums. We take the daily average of the log change in the various CDS premiums/indexes for the days between auctions. 


\section{Empirical Results and Interpretation of Results}

\subsection{Results: Pre-Crisis VAR}

Tables 1(a) and 1(b) follow the schema for the parameter array shown in Section 3 and contain results for an unrestricted estimation of the modified-VAR. Overall, the estimates have intuitive appeal and there is a high proportion of variation in the dependent variables explained by the regression (this is evidenced by a comparison of variances of residuals and those of the dependent variables with $R^{2}$ in the region of $68 \%$ and $60 \%$ for the auction settlement-rate equation and the repo-market trade volume equation respectively). Tests on the residuals show no sign of auto-correlation or autoregressive conditional heteroscedasticity.

There are interesting differences between the 'within' and 'across' maintenance period effects. ${ }^{15}$ In most cases, the within maintenance period AR coefficient is larger and more statistically significant than the effect involving cross-over into the previous maintenance period. There does not appear to be significant accentuation of the autoregression for the last auction (indeed there is a negative sign on the own-autocorrelation of the auction variable for the last auction).

The positive own-autocorrelation in the auction equation displayed in Table 1(a), denoted as $a_{i, 11}$ for the 'within' and 'across' period effects, is very significant as would be expected from a persistent auction policy. There is a switch in sign of this auto-correlation at the end of the year. The relation between the excess auction rate and interbank repo roll-over volume is captured by the $a_{i, 12}$ parameters. The first of these is a contemporaneous effect and it is very significant and negative. This is consistent with our priors that interbank activity is, to some degree, a substitute for auction participation (or for aggressive bidding in auctions). However, the cross-effect has a different sign for the last auction (which is also statistically significant). The lagged within-period cross-effect from the repo market to auction outcomes are statistically insignificant.

The interbank equation displayed in Table 1(b) has very few individually significant parameters. The constants explain a large proportion of the variation in the dependent

\footnotetext{
${ }^{15}$ We do not attempt an interpretation of the constants since these are really combinations of mean effects in both equations but it is clear that there is a large turn-of-year effect.
} 
variable and these reveal a large turn-of-year effect. Auction spill-over to the repo market is captured by the $a_{i, 21}$ parameters and the within-period effect is positive and significant for the first lag but otherwise insignificant. There is a strong turn-of-year cross-effect at lag 2. The own-autoregression for the repo roll-over variable is almost always individually insignificant.

Block exogeneity tests produced the following results. The test of exclusion of all 22 repo variables from the auction equation produced a Chi-Squared $(22)=72.189$ which has a p-value of less than 0.010 and therefore implies causality of some kind from repo roll-over to auction bidding. The test for exclusion of the cross-effects in the auction equation that are relating to a previous maintenance period $\left(a_{2,12,2}, a_{3,12,2}\right.$ and $\left.a_{4,12,2}\right)$ produces a ChiSquared $(3)=4.302$ with p-value 0.231 . This implies that only within maintenance period cross effects are important. Similarly the test of exclusion of the 18 auction variables from the repo market equation produced a Chi-Squared $(18)=41.444$ with a p-value of less than 0.010 and this also implies causality from auctions to repo activity. The test for exclusion of the cross-effects in the repo equation that are relating to a previous maintenance period $\left(a_{2,21,2}, a_{3,21,2}\right.$ and $\left.a_{4,21,2}\right)$ produces a Chi-Squared(3) $=3.108$ with p-value 0.375. Again, this implies that cross-equation effects do not traverse maintenance periods.

\subsubsection{Interest rate events}

The residuals from the VAR represent the unexpected outcomes of the dependent variables of the VAR controlling for the seasonality. We use these to construct a Cumulative Average Abnormal Response (CAAR) analysis around the eight interest rate moves that took place from Nov 2005 to June 2007. We show the results of the CAAR analysis in Figure 8. They indicate that there is a rise in cumulative roll-over of repos in the period preceding these events on average of about $4 \%$. There is a significant downturn in activity after the event (one that more-than-reverses the average pre-event increase). There is a very slight effect in the weighted average auction rates which also seems to be consistent with banks forward filling their needs in the auctions before the interest rate increases.

We ran alternative VAR regressions that included microstructure developments in the repo market to see if the cumulative effect of the event was in some way related to market structure developments. The outcome was robust to these inclusions; we regard this as 
tentative evidence that the effect was entirely due to the interest rate effect. The size of the contraction following the interest rate events and the speed of their occurrence is a feature worthy of further analysis. On the basis of, the well known, "long and variable lags" with which monetary policy is expected to have effects there are grounds for suspicion that these contractions are more than just normal monetary policy effects. We suspect that this is more likely due to a deterioration in collateral quality on banks balance sheets (such the credit quality of such assets would be positively correlated with the policy rate). This is admittedly only tentative evidence and we leave further analysis - and more rigorous testing of this proposition - for future work.

\subsection{Results: Crisis Periods}

Table 2 contains combined auction regression results for the first and second phases of the financial crisis. The Crisis I period ends just before the Lehman event and the Crisis II sample begins with the introduction of fixed rate full allotment auction (which was soon after the Lehman event). Regressions (1) to (3) concern the weighted average settlement rate as the dependent variable. The goodness of fit, $\bar{R}^{2}$, is $13 \%$ for regression (2) which was the model that we selected as a source of residuals for the supplementary regression. The main result of interest here is the significant negative coefficient on recent repo market average daily volume. A higher than normal volume is associated with reduced aggressiveness of bidding in the auction that follows. This is consistent with the assertion that good sharing of liquidity within the repo market reduces the urgency by rationed banks to obtain funding at auctions. Other notable aspects of the first three regressions include a strong turn-of-year effect and a residual that does not have a significant MA(1) coefficient as would have been consistent with our structural model. By reference to equation (3) above we see that this implies an insignificant shared transitory component in the structural model. We note that this does not rule out an MA(1) structure for the supplementary regression and there remains a role for the lagged residual from the auction regression in the supplementary regression.

Regressions (4) to (6) concern the excess auction allotment relative to maturing amounts from a previous similar auction as the dependent variable. The goodness of fit, $\bar{R}^{2}$, is roughly $47 \%$ in these cases. The test of exclusions does not support a move from regression (4) to (6) and we selected regression (5) as a source of residuals for the supplementary 
regression (the results of the supplementary regression are not sensitive to this selection). There is a negative coefficient on recent repo market average daily volume in these regressions but the coefficient estimate is never statistically significant. If the ECB wants to avoid a divergence in the marginal settlement rate from the intended policy rate then we would expect allotment to increase if aggressive bidding in the auctions becomes widespread among participating banks. If aggressive bidding is widespread, the originally intended allotment quantity will be used up before the marginal rate declines to the policy target. On this basis we would expect a positive relationship between aggressive bidding (the weighted average settlement rate) and the allotment innovations. We would also therefore expect a negative coefficient on the allotment innovations and repo market trading activity. The sign of the coefficient on repo volume in regressions (4) to (6) is negative as expected but insignificant.

Regressions (4) to (6) also include a large and significant turn-of-year effect and an end-of-maintenance period effect (the Last dummy variable allows a different level effect in the last operation of the maintenance period). The coefficient on the dummy variable indicating that the previous operation was an LTRO auction, $\left(L T R O_{t-1}\right)$, is also significantly negative. This could be indicative of a substitution effect between these types of operation. Finally, the residual in regression (4) has a significant MA(1) process which is consistent with a shared transitory component in the structural model but it becomes insignificant in the restricted models.

The last three regression results presented in Table 2 concern the second crisis period. In this case there is only an allotment variable to consider (since the settlement rate is fixed). An immediately obvious difference between these regression results and those for the Crisis I period concerns the decline in the goodness of fit measure to less than $5 \%$. There is clearly a diminished ongoing relationship between the two funding venues for this period. There remains a significant end-of-maintenance period effect but the effect from previous LTROs is opposite in sign to what was found for the Crisis I period. More importantly, there is no relationship between auction allotment and average daily repo market activity until a second lag of average daily repo activity is included and this effect is positive rather than negative as would be expected if the venues are substitutes for each other.

We now consider the regression results for the supplementary regressions tabulated in 
Table 3. These regression results also cover the crisis period and the main question is whether the residuals from the relevant regressions in Table 2 make any contribution to explaining average daily repo market activity in the days after auctions (in the case of the Crisis I period we include residuals from both the settlement rate regression, Resid: $\dot{P}_{t-1}^{a u c}$, and the allotment regression, Resid : $\left.\dot{Q}_{t-1}^{a u c}\right)$. We also expect a reduction in the auto-correlation of the error term in the repo activity regression when the various control variables are included.

The first three regressions in Table 3 involve the use of control variables based on the change in the log of CDS spreads for sovereign bonds and for simple CDS indexes of the main banks within a number of periphery countries and for Germany. These CDS spreads become unreliable in the second crisis period and for this reason we compare results for both periods using repo market microstructure variables (spread and depth measures) as controls in regressions (4) to (9). In unrestricted regressions (and in restricted regressions where it remains significant) we also include the Euribor-OIS spread.

In the Crisis I period there is ample evidence for a link between repo market activity and auction behaviour. All of the Crisis I regressions have goodness of fit measures in excess of $40 \%$. There are quite a number of the controls that are significant in both sets of models but coefficient signs are not easily interpreted, which probably reflects the fact that many of these are correlated with each other. ${ }^{16}$ It is interesting that the control variables with most statistical significance from the two different groups are associated with almost the same set of countries (Germany, Italy and Portugal feature prominently).

We turn now to a discussion of the cross-effects from auction outcomes. Firstly, the residuals from the auction allotment equation always have a negative sign (even in the Crisis II period). However, these coefficients are not statistically significant at conventionally acceptable levels. This therefore gives meta-support for the expected effect but otherwise very weak evidence of a benign substitution effect flowing from auctions to the post-auction repo market.

The price effect in all six of the Crisis I regressions is highly significant (i.e., significant at better than $99 \%$ level of confidence). However, the price effect is also positive. This indicates that the price effect from aggressive bidding in auctions outweighs any benign

\footnotetext{
${ }^{16}$ We conducted the analysis using the principal components of the controls and this produced similar results more parsimoniously (results are available from the authors on request).
} 
distributional effects associated with funding going disproportionally to the most needy banks.

The results for the second crisis period shows a complete lack of any relationship between interbank market activity and auction allotment. We regard the results for the second crisis period as indicative of a separation in the type of participants in the two

funding venues. The repo market has high quality counterparties dealing with each other at repo rates below the fixed rate that is available from ECB auctions. In contrast, participants in auctions are most likely to be those that are unable to access the interbank market either because they have insufficient high quality collateral or because they are known to be be highly risky counter parties.

\section{Conclusion}

This paper examines the relationship between secured interbank lending activity in the Euro Area using sovereign bonds as collateral and the outcomes of the ECB's liquidity providing operations. The analysis considers the pre-crisis period and then two different auction regimes within the crisis sample. In the pre-crisis sample a VAR approach is used to uncover the causal linkages between the two funding sources with allowances made for different types of seasonality. A structural model is proposed for the crisis period and this gives rise to a modified-VMA representation and a sequential empirical methodology that is capable of identifying how auctions matter for interbank activity when the interbank market is affected by changes in the quality of counterparties and by collateral and liquidity hoarding shocks.

The analysis of the pre-crisis period indicates that outcomes of official funding operations have direct effects on interbank repo market activity. Seasonality is a significant feature of the relationship. The effects of outcomes of operations in the pre-crisis period are statistically significant but not very large. It seems likely that the amount of official funding provided (and its terms) did not act as a binding constraint on the use of short term funding for most of the pre-crisis period following the bursting of the dot-com bubble. There was a significant growth in repo market activity (that is likely to be, to some extent, related to a more connected and integrated network for the sharing of liquidity across the Euro Area banking sector). This meant that official funding became an increasingly 
smaller proportion of the volume of interbank activity (and therefore less of a significant constraint). Despite the continued broadening of funding opportunities, due to improved trading infrastructure, an event analysis of interest rate increases shows that monetary policy was effective in constraining the use of such funding in the period from November 2005 to mid-2007. The slack funding conditions in the 2003-2005 period may have produced the vulnerabilities that were subsequently revealed by the crisis (i.e., banks may have become overly reliant on seemingly dependable opportunities to roll-over cheap funding using plentiful collateral and this left them vulnerable when collateral quality declined and counterparty risk increased, and when there was hoarding of reserves and collateral).

The analysis of the crisis period shows that access to official funding can work in different ways to ameliorate the effects of the contraction of the sharing of liquidity in the repo market. Firstly, it is possible that aggressive bidding in auctions, by those banks with the fewest opportunities for interbank funding, may produce a better allocation of funding to where it is most needed (i.e., the aggressive bidders take a disproportionate amount of the funding on offer). This could also encourage banks with better interbank access to favour interbank funding due to the weighted average price rise, the price-effect, or simply because such under-bidding banks are more likely to be left without allocations if the marginal rate is allowed to rise. More directly, since there were some changes in the amount allotted in auctions even before full-allotment was introduced, this could have directly affected the amount of sharing of liquidity that was required in the interbank market. However, our analysis shows that the price effects from aggressive bidding led to increased post-auction activity and this implies that the price effect was greater than either the allocation effects or from the quantity effect due to increased overall allotment (although we find the correct sign on the quantity effect). The post-Lehman period (when fixed-rate full-allotment was introduced) seems to be consistent with an over-provision of liquidity and a reduced (insignificant) interaction between the two funding sources. We interpret this as evidence of a separation of the market into 'good' and 'bad' banks with the latter dependent on official funding and the former prepared to transact in the interbank market at a repo rate that is significantly below the fixed rate available in auctions.

Overall, the analysis of the pre-Lehman crisis period points to a trade-off between quantity and price effects that could be harnessed by policy makers when returning to more normal variable-rate operations. We have found that the price-effects from aggressive 
bidding in variable rate auctions drives some banks back to private sharing of funding and this could be viewed as a good development. However, this could also lead to too large a separation of the auction rate from the intended policy rate and this would be undesirable from the point of view of monetary policy transmission. Therefore, to avoid extreme weighted average settlement rates in auctions, allotment quantity could be varied (initially increased) to attenuate extreme aggressive bidding. Our analysis gives some indication that increased allotment quantity would subdue interbank market stresses during the transition. Over time, a schedule of progressively declining allotment quantities could be announced to allow banks to prepare for the planned adjustment. As the analysis above shows, the price and quantity effects from such auctions on repo market activity can be monitored and measured and therefore allotment quantity could be adjusted towards an optimal level as required. 


\section{References}

[1] Berger, H., J. de Haan \& J. Sturm. (2011). "Does Money Matter in the ECB Strategy? New Evidence Based on ECB Communication." International Journal of Finance and Economics, 16:16-31.

[2] Bindseil, U., K. Nyborg \& I. A. Strebulaev. (2009). "Repo Auctions and the Market for Liquidity." Journal of Money Credit and Banking, 41: 1391-1421.

[3] Borio, C. \& W. Nelson. (2008). "Monetary Operations and The Financial Turmoil." BIS Quarterly Review March 2008, 32-45.

[4] Brunetti, C., M. di Filippo \& J. Harris. (2009). "Effects of Central Bank Intervention on the Interbank Market: What Happened during the Sub-prime Crisis?" Review of Finanical Studies, 24(6):2053-2083.

[5] Carpenter, S. B., \& S. Demiralp. (2006a). "Anticipation of Monetary Policy and Open Market Operations." International Journal of Central Banking, June 2006, 25-63.

[6] Carpenter, S. B., \& S. Demiralp. (2006b). "The Liquidity Effect in the Federal Funds Market: Evidence from Daily Open Market Operations." Journal of Money, Credit 85 Banking, June 2006, 901-920.

[7] Cour-Thimann, P. \& B. Winkler. (2013). "The ECB's Non-Standard Monetary Policy Measures; The Role of Institutional Factors and Financial Structure." European Central Bank Working Paper Series, April 2013, No. 1528.

[8] Drehmann, M \& K. Nikolau. (2009). "Funding liquidity risk: definition and measurement." ECB working paper No. 1024.

[9] Drehmann, M \& K. Nikolau. (2013). "Funding liquidity risk: definition and measurement." Journal of Banking and Finance, 37,2173-2182.

[10] ECB. (2009). "ECB Financial Stability Report." European Central Bank, Eurosystem. available at http://www.ecb.int/pub/pdf/other/ financialstabilityreview200906en.pdf 
[11] ECB. (2008). "General Documentation on Eurosystem Monetary Policy Instruments and Procedures." European Central Bank, Euro System 2008. available at http://www . ecb.int/pub/pdf/other/gendoc2008en.pdf.

[12] Eisenschmidt, J., A. Hirsch \& T. Linzert. (2009). "Bidding Behaviour in the ECB's Main Refinancing Operations during the Financial Crisis." European Central Bank Working Paper, No. 1052.

[13] Heider, F., M. Hoerova \& C. Holthausen. (2009). "Liquidity Hoarding and Interbank Market Spreads: The Role of Counterparty Risk." European Banking Center Discussion Paper No. 2009-11S. Available at SSRN: http://ssrn.com/abstract=1362113.

[14] Hördahl, P., \& M. R. King. (2008). "Developments in Repo Markets During the Financial Turmoil." BIS Quarterly Review pp 37-53.

[15] Issing, O. (2006). "The ECB's Monetary Policy Strategy: Why did we choose a two Pillar Approach?" Contribution to: The role of money: money and monetary policy in the twenty-first century. 4th ECB Central Banking Conference.

[16] Lütkepohl, H. (2005). "New Introduction to Multiple Time Series Analysis." SpringerVerlag, Berlin.

[17] Mancini, L., Ranaldo, A. and Jan Wrampelmeyer. (2013). "The euro repo market." University of St. Gallen Working Paper.

[18] Sims, C. A. (1980). "Macroeconomics and Reality." Econometrica (48), 1-49. 


\section{Figures}

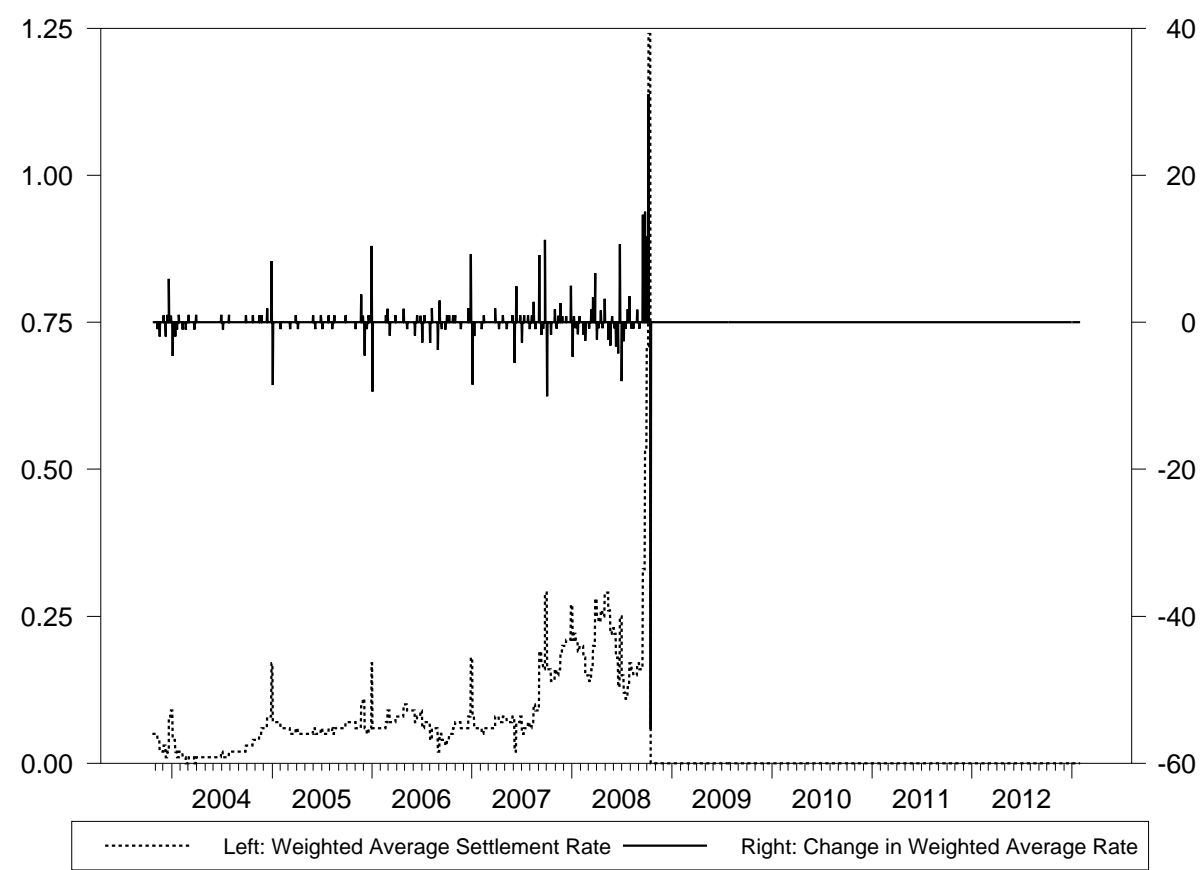

Figure 1: This figure shows the weighted average settlement rate as a deviation from the ECB target rate (on the chart baseline and measured against the scale on the left axis) and the change in the weighted average settlement rate relative to the ECB marginal lending rate (upper section of graph space and measured against the scale on the right axis).

Note: Amounts are in basis points (right axis) and percentages (left axis). When the fixed-rate full allotment auctions apply the auction rate equals the policy rate and both variables are zero. 


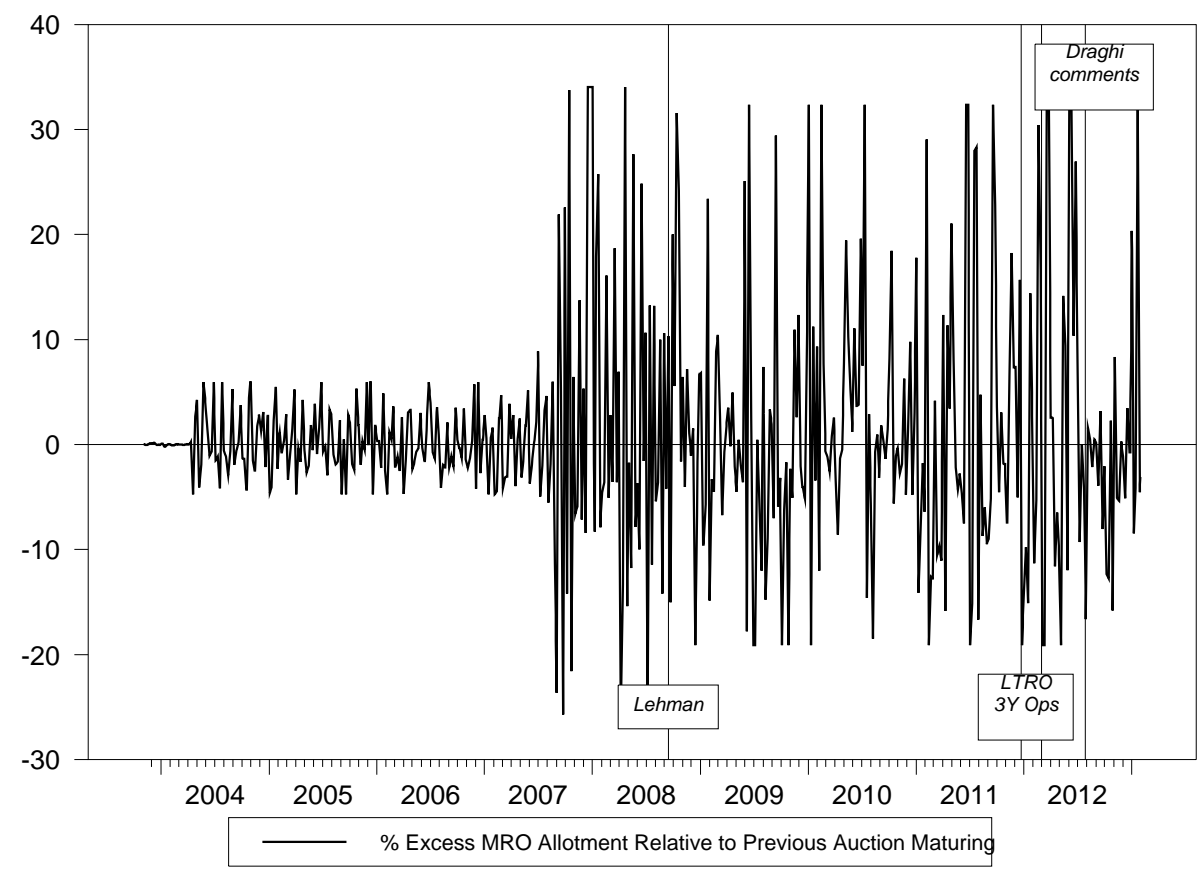

Figure 2: This figure shows the amount allotted in MRO auctions in excess of maturing amounts from the previous auction as \% of maturing amounts.

Note: Amounts are percentage points. 


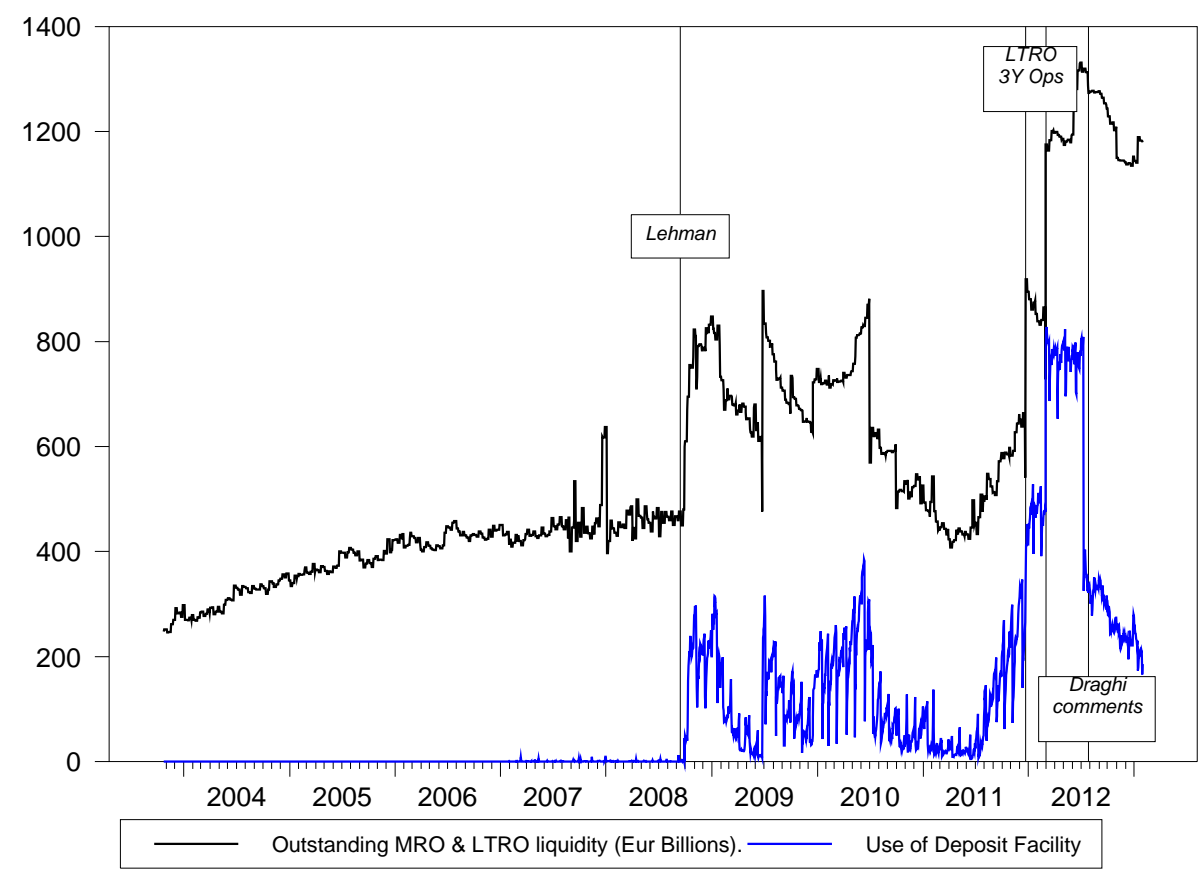

Figure 3: The liquidity provided through MRO and LTRO operations is shown along-side the amount of liquidity deposited in the ECB's Deposit Facility.

Note: Amounts are shown in billions of euro. 


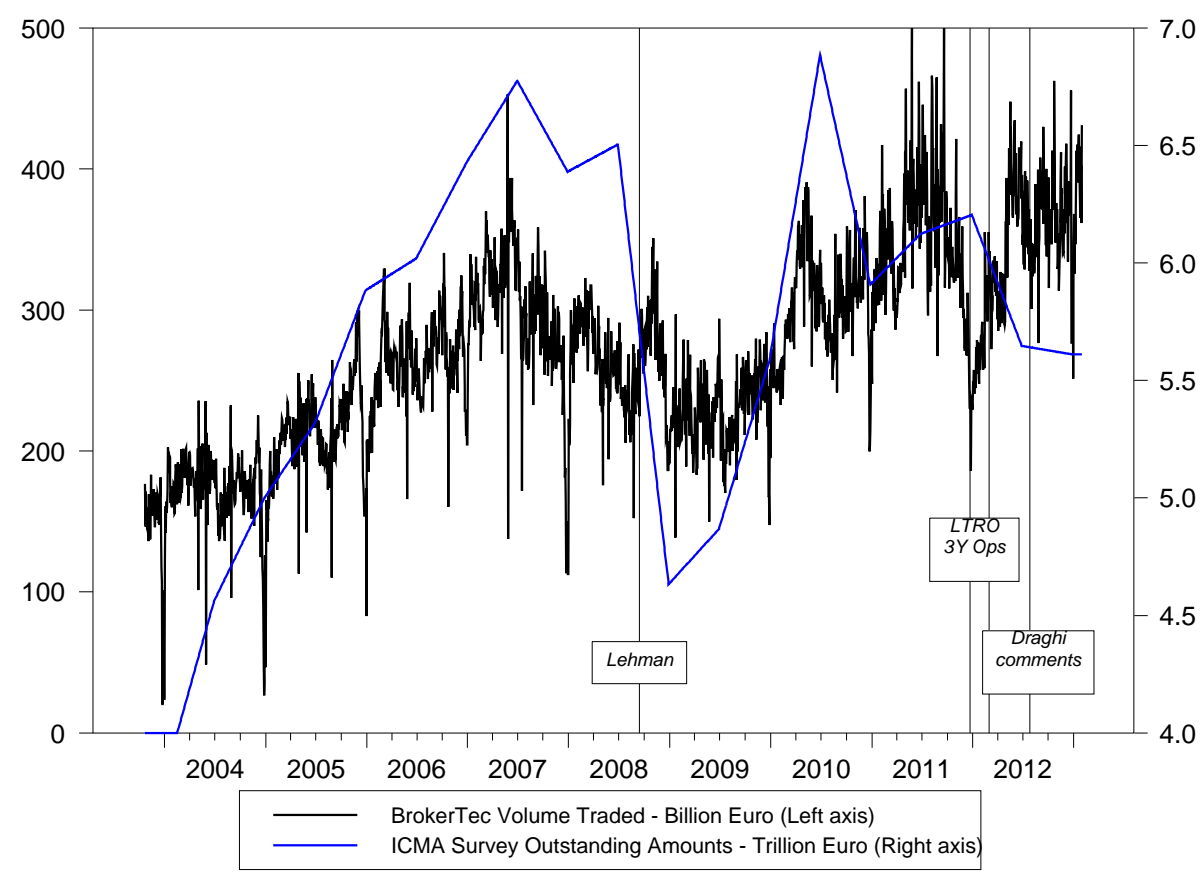

Figure 4:Repo volume ICMA Survey and BrokerTec ATS.

Note: The BrokerTec daily volume of trading in repos using sovereign collateral issued by ten Euro Area sovereigns is shown in billions of euro. Also shown is the six monthly survey of outstanding amounts of repo transactions (in trillions of euro) of roughly 70 of the largest banks in the European Union where there is linear interpolation between the observed amounts. 


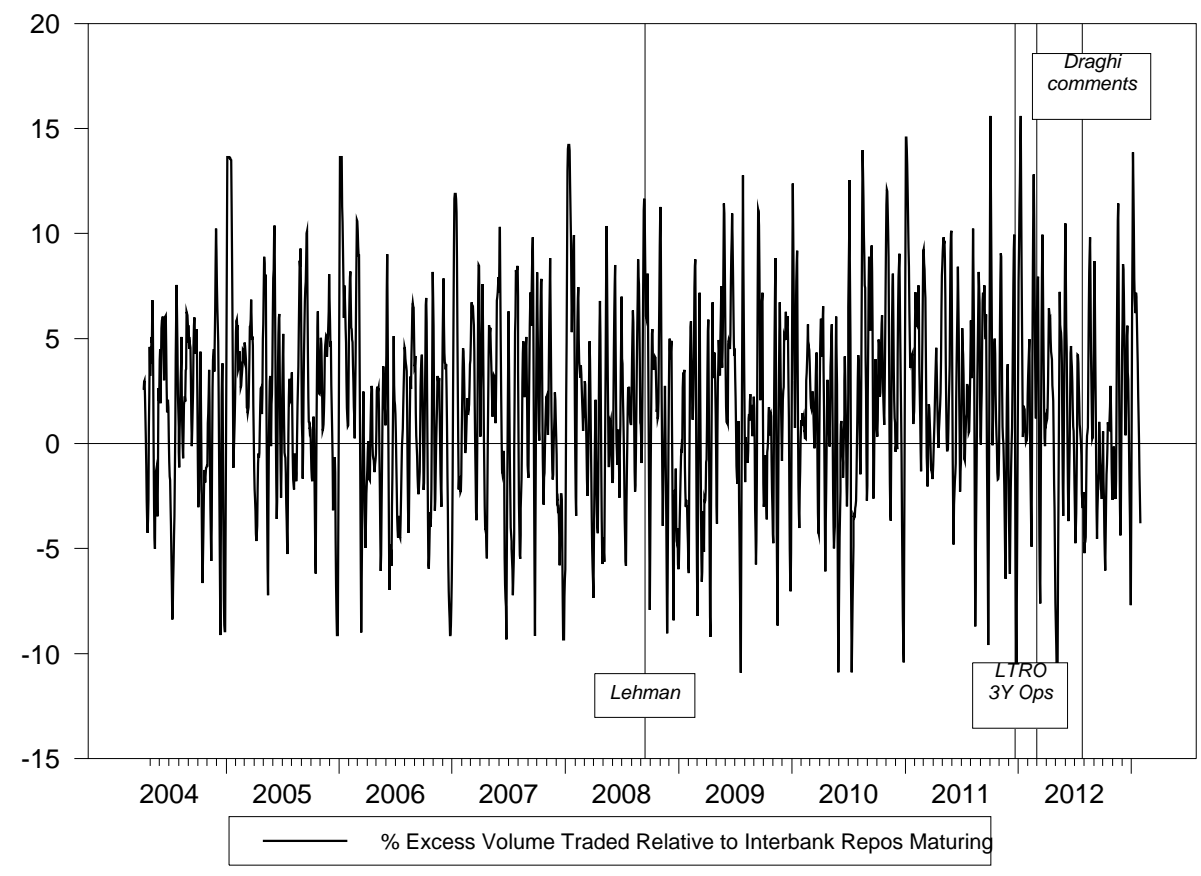

Figure 5: Traded volume on BrokerTec ATS in Excess of Maturing Amounts as \% of Maturing Amounts.

Note: To help in visualizing the main movement in this series we display the 5 day moving average of the raw series. Also, observations exceeding the $5 \%$ tails of the data are capped at the tail percentile levels. 

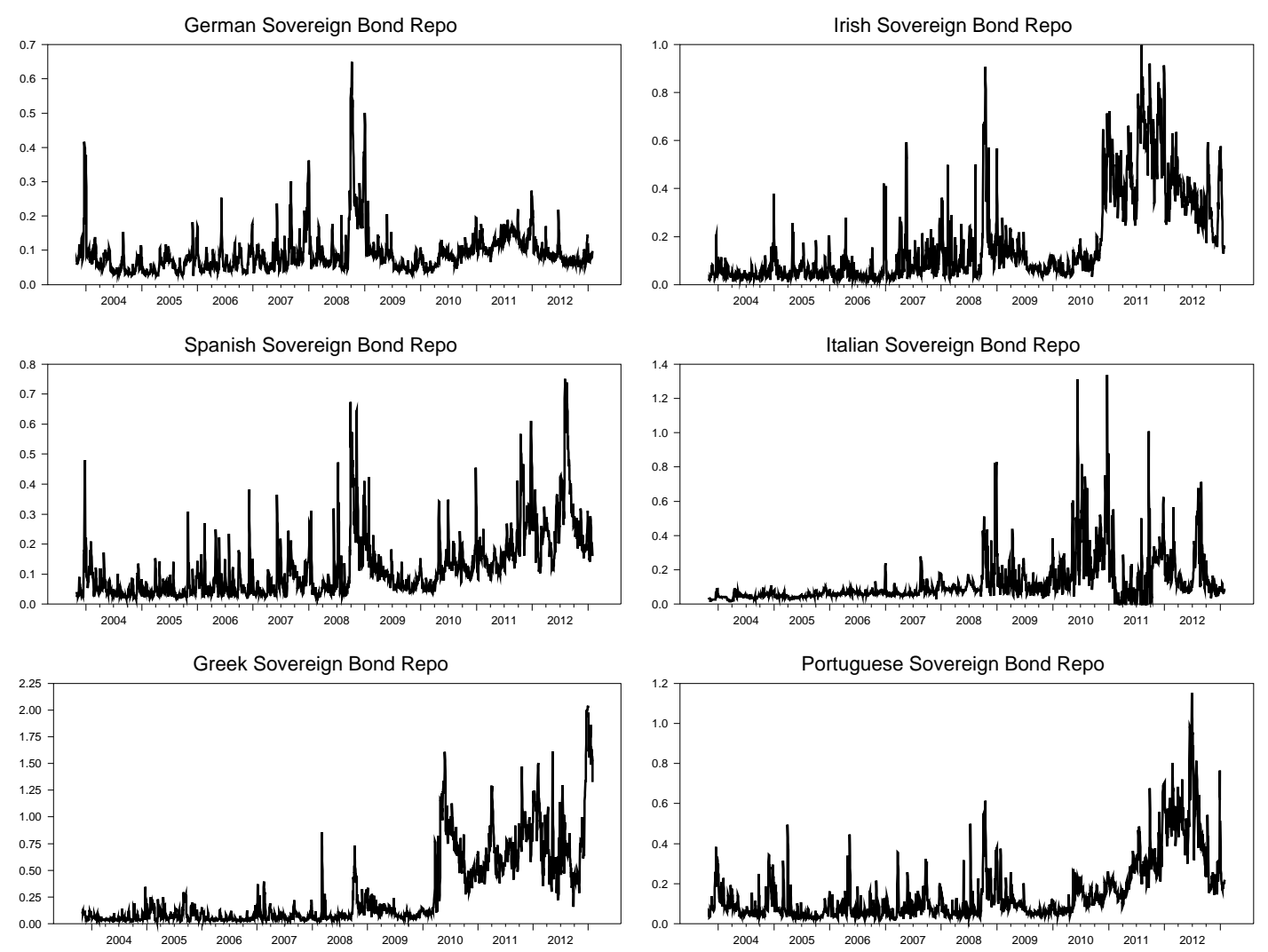

Figure 6: The log of the time weighted average bid ask spread in basis points for repos based on selected sovereign collateral.

Note: The spread within each market is first time-weighted (where only two-sided quoting is timed) and then averaged across term-specific contracts. 

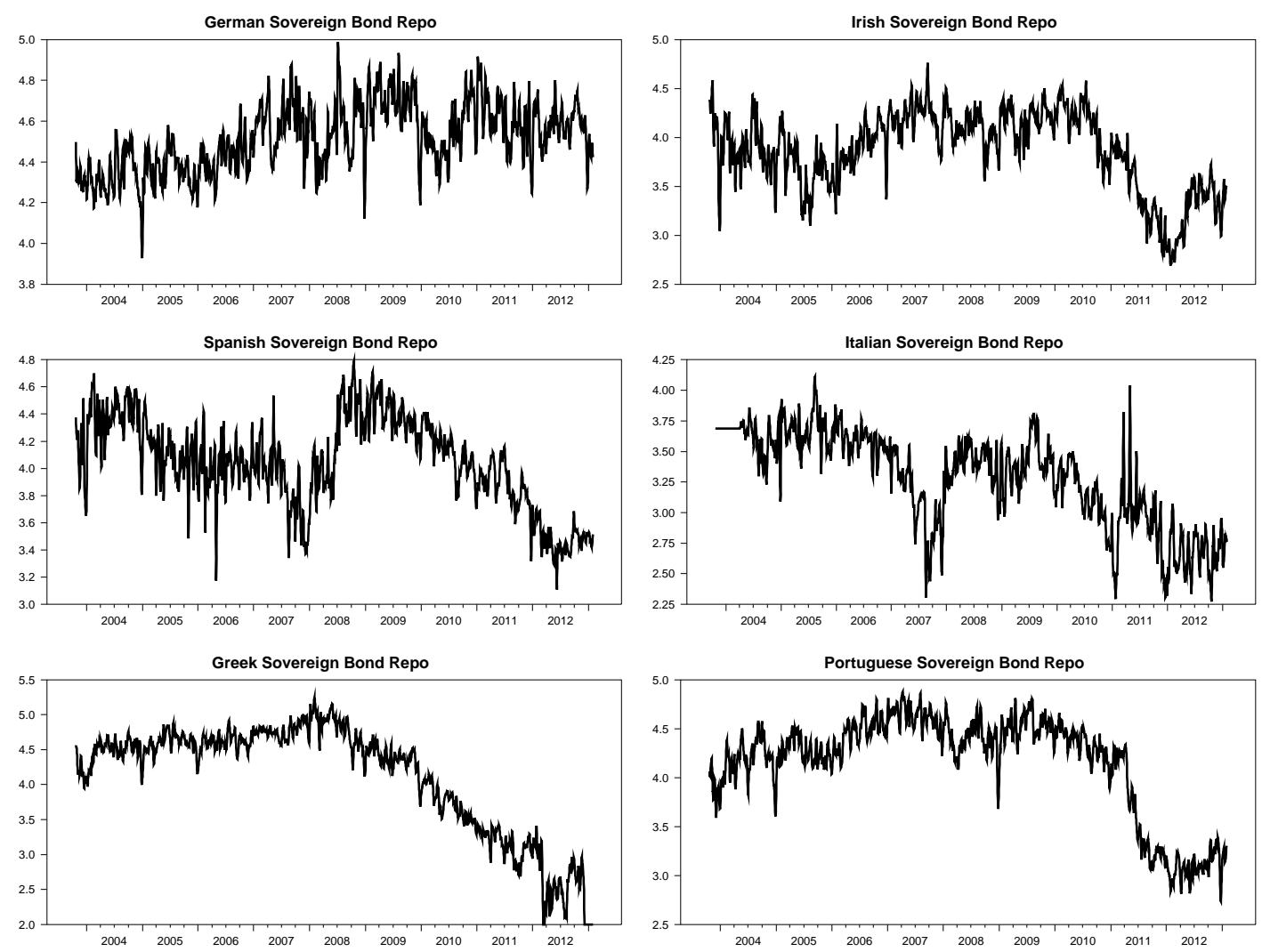

Figure 7: The log of the quantity on the orderbook (million euro) for repos based on selected sovereign collateral.

Note: The full book is included in this calculation. All variables have been smoothed using a 5 day centered moving average. The raw variables are used in the regression analysis. 


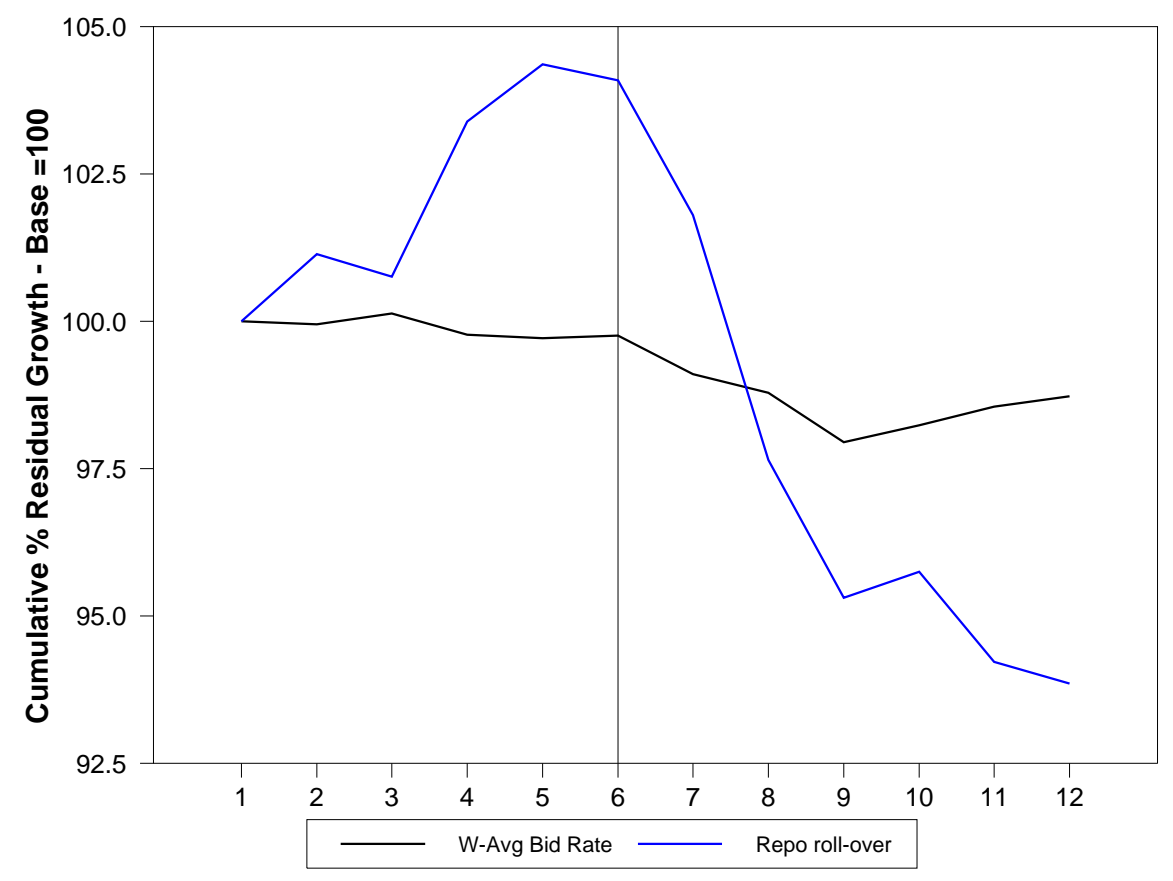

Figure 8: Cumulative percentage residuals for the weighted average auction rate and for repo rollover around interest rate changes.

Note: The residuals from the VAR regression outlined in Section 3 are used to assess cumulative average effects on auction outcomes and interbank repo volume traded. The figure indicates that there is a rise in volume before interest rate changes and then a sharp decline after the event (cumulatively about $7 \%$ down from the five auctions before the event. The effect for the case of auction weighted average settlement rate is much more subdued. 


\section{Tables}

\begin{tabular}{|c|c|c|c|c|c|c|}
\hline & \multicolumn{6}{|c|}{ Dependent Variable: $P_{\bar{t}}^{a u c}$} \\
\hline & Within & Across & Last & $E O Y_{\{a, b\}}$ & $L T R$ & LTRL \\
\hline \multirow[t]{2}{*}{$a_{0,01}$} & $\begin{array}{l}1.088^{\bar{*}} \\
(0.274)\end{array}$ & & $\begin{array}{r}-0.793^{*} \\
(0.458)\end{array}$ & $\begin{array}{r}2.57^{\overline{\bar{*}}} \\
(0.843)\end{array}$ & $\begin{array}{r}-2.478^{\bar{*}} \\
(1.143)\end{array}$ & \\
\hline & & & & $\begin{array}{l}8.618^{\bar{*}} \\
(2.427)\end{array}$ & & \\
\hline$a_{1,12}$ & $\begin{array}{r}-0.091^{\bar{*}} \\
(0.037)\end{array}$ & & $\begin{array}{c}0.127^{\bar{*}} \\
(0.064)\end{array}$ & $\begin{array}{c}-0.002 \\
(0.057)\end{array}$ & $\begin{array}{c}-0.037 \\
(0.113)\end{array}$ & \\
\hline$a_{2,11}$ & $\begin{array}{r}0.592^{\overline{\bar{*}}} \\
(0.14)\end{array}$ & $\begin{array}{r}0.525^{\bar{*}} \\
(0.127)\end{array}$ & $\begin{array}{r}-0.436^{\bar{*}} \\
(0.174)\end{array}$ & $\begin{array}{r}-0.604^{\bar{*}} \\
(0.187)\end{array}$ & $\begin{array}{c}0.478^{\bar{*}} \\
(0.223)\end{array}$ & $\begin{array}{r}-0.326^{\bar{*}} \\
(0.123)\end{array}$ \\
\hline$a_{2,12}$ & $\begin{array}{c}0.061 \\
(0.045)\end{array}$ & $\begin{array}{c}-0.032 \\
(0.034)\end{array}$ & $\begin{array}{c}-0.044 \\
(0.053)\end{array}$ & $\begin{array}{r}-0.115^{\bar{*}} \\
(0.052)\end{array}$ & $\begin{array}{c}-0.096 \\
(0.059)\end{array}$ & $\begin{array}{r}-0.102^{*} \\
(0.061)\end{array}$ \\
\hline$a_{3,11}$ & $\begin{array}{c}0.299^{*} \\
(0.157)\end{array}$ & $\begin{array}{l}0.236 \\
(0.151)\end{array}$ & $\begin{array}{c}-0.013 \\
(0.234)\end{array}$ & $\begin{array}{c}-0.155 \\
(0.218)\end{array}$ & $\begin{array}{c}0.169 \\
(0.265)\end{array}$ & $\begin{array}{r}-0.333^{\bar{*}} \\
(0.152)\end{array}$ \\
\hline$a_{3,12}$ & $\begin{array}{c}-0.006 \\
(0.029)\end{array}$ & $\begin{array}{c}-0.033 \\
(0.025)\end{array}$ & $\begin{array}{c}0.107^{\overline{\bar{*}}} \\
(0.039)\end{array}$ & $\begin{array}{r}-0.054 \\
(0.042)\end{array}$ & $\begin{array}{c}0.274 \\
(0.212)\end{array}$ & $\begin{array}{r}-0.118^{\bar{*}} \\
(0.041)\end{array}$ \\
\hline$a_{4,11}$ & $\begin{array}{c}0.194 \\
(0.139)\end{array}$ & $\begin{array}{c}0.048 \\
(0.046)\end{array}$ & $\begin{array}{c}0.602^{\bar{*}} \\
(0.191)\end{array}$ & $\begin{array}{r}-0.573^{\bar{*}} \\
(0.216)\end{array}$ & $\begin{array}{c}-0.498 \\
(0.306)\end{array}$ & $\begin{array}{r}-0.422^{\bar{*}} \\
(0.138)\end{array}$ \\
\hline$a_{4,12}$ & $\begin{array}{c}0.011 \\
(0.022)\end{array}$ & $\begin{array}{l}0.007 \\
(0.014)\end{array}$ & $\begin{array}{c}-0.03 \\
(0.04)\end{array}$ & $\begin{array}{r}-0.198^{\bar{*}} \\
(0.09)\end{array}$ & $\begin{array}{r}-0.023 \\
(0.12)\end{array}$ & $\begin{array}{c}0.056 \\
(0.065)\end{array}$ \\
\hline $\mathrm{RCH}_{\epsilon}$ & & {$[0.873]$} & & $\mathrm{L}-\mathrm{B}_{\epsilon}$ & {$[0.7$} & \\
\hline
\end{tabular}

Table 1: (a). Regression results for the pre-crisis period for the auction equation of the VAR model outlined in Section 3.1 are presented. The number of observations is 203 which includes all official operations by the ECB between 6th June 2004 and 12th June 2007. Coefficient estimates are displayed with standard errors in parentheses $(\overline{\bar{*}}, \bar{*}$ and $*$ respectively indicate sizes of the underlying p-values as follows; $p<0.01,0.01<p<0.05$ or $0.05<p<0.10)$. The dependent variable is the percentage deviation between the weighted average auction rate and the ECB's deposit rate. Parameter estimates for different interactive dummy variables are provided in the columns denoted; Within, Across, Last, EOY, LTR and LTRL. In the bottom row of the table we present tests for AR and ARCH effects in the residual. Specifically, the p-values for Ljung-Box Q-statistics for residual autocorrelation of up to order 3 and for $\mathrm{ARCH}(1)$ effects are provided. Estimation was done with the RATS software package and implemented with the 'Maximize' function including the 'Robust' option for heteroscedasticity/misspecification adjusted standard errors. 


\begin{tabular}{|c|c|c|c|c|c|c|}
\hline & \multicolumn{6}{|c|}{ Dependent Variable: $Q_{\bar{t}}^{\text {repo }}$} \\
\hline & Within & Across & Last & $E O Y_{\{a, b\}}$ & $L T R$ & LTRL \\
\hline \multirow[t]{2}{*}{$a_{0,02}$} & $\begin{array}{l}-1.33 \\
(1.016)\end{array}$ & & $\begin{array}{c}4.173^{\bar{*}} \\
(2.061)\end{array}$ & $\begin{array}{r}-10.932^{*} \\
(4.916)\end{array}$ & $\begin{array}{l}4.339^{\bar{*}} \\
(2.13)\end{array}$ & \\
\hline & & & & $\begin{array}{r}29.572^{\bar{*}} \\
(11.272)\end{array}$ & & \\
\hline$a_{2,21}$ & $\begin{array}{c}0.682^{\bar{*}} \\
(0.274)\end{array}$ & $\begin{array}{c}0.353 \\
(0.35)\end{array}$ & $\begin{array}{c}-0.196 \\
(0.517)\end{array}$ & $\begin{array}{r}-0.273 \\
(0.8)\end{array}$ & $\begin{array}{c}-0.619 \\
(0.432)\end{array}$ & $\begin{array}{r}-0.426^{*} \\
(0.254)\end{array}$ \\
\hline$a_{2,22}$ & $\begin{array}{c}-0.062 \\
(0.179)\end{array}$ & $\begin{array}{c}-0.224 \\
(0.199)\end{array}$ & $\begin{array}{c}-0.136 \\
(0.235)\end{array}$ & $\begin{array}{c}0.173 \\
(0.21)\end{array}$ & $\begin{array}{c}-0.129 \\
(0.191)\end{array}$ & $\begin{array}{r}0.579^{\overline{\bar{F}}} \\
(0.214)\end{array}$ \\
\hline$a_{3,21}$ & $\begin{array}{c}0.151 \\
(0.368)\end{array}$ & $\begin{array}{c}0.076 \\
(0.368)\end{array}$ & $\begin{array}{c}0.77 \\
(0.746)\end{array}$ & $\begin{array}{r}-3.002^{\overline{\bar{*}}} \\
(0.787)\end{array}$ & $\begin{array}{c}0.277 \\
(0.439)\end{array}$ & $\begin{array}{c}-0.848 \\
(0.662)\end{array}$ \\
\hline$a_{3,22}$ & $\begin{array}{r}-0.028 \\
(0.08)\end{array}$ & $\begin{array}{c}-0.102 \\
(0.122)\end{array}$ & $\begin{array}{c}0.437 \\
(0.301)\end{array}$ & $\begin{array}{c}-0.391 \\
(0.283)\end{array}$ & $\begin{array}{c}-0.138 \\
(0.409)\end{array}$ & $\begin{array}{c}-0.283 \\
(0.313)\end{array}$ \\
\hline$a_{4,21}$ & $\begin{array}{r}-0.168 \\
(0.37)\end{array}$ & $\begin{array}{c}-0.424 \\
(0.277)\end{array}$ & $\begin{array}{c}-0.526 \\
(0.675)\end{array}$ & $\begin{array}{l}1.956^{\bar{*}} \\
(0.964)\end{array}$ & $\begin{array}{l}0.247 \\
(0.582)\end{array}$ & $\begin{array}{c}-0.192 \\
(0.728)\end{array}$ \\
\hline$a_{4,22}$ & $\begin{array}{c}0.173^{*} \\
(0.102)\end{array}$ & $\begin{array}{c}0.083 \\
(0.066)\end{array}$ & $\begin{array}{r}-0.327 \\
(0.215)\end{array}$ & $\begin{array}{c}0.41 \\
(0.594)\end{array}$ & $\begin{array}{c}0.384 \\
(0.415)\end{array}$ & $\begin{array}{l}-1.07^{*} \\
(0.587)\end{array}$ \\
\hline $\mathrm{ARCH}_{\epsilon}$ & & {$[0.998]$} & & $\mathrm{L}-\mathrm{B}_{\epsilon}$ & {$[0.4$} & \\
\hline
\end{tabular}

Table 1: (b). Regression results for the pre-crisis period for the repo equation of the VAR model outlined in Section 3.1 are presented. The number of observations is 203 which includes all official operations by the ECB between 6th June 2004 and 12th June 2007. Coefficient estimates are displayed with standard errors in parentheses $(\bar{*}, \bar{*}$ and $*$ respectively indicate sizes of the underlying p-values as follows; $p<0.01,0.01<p<0.05$ or $0.05<p<0.10)$. The dependent variable is the average percentage excess/shortfall in roll-over of maturing repos within the period between ECB auctions. Parameter estimates for different interactive dummy variables are provided in the columns denoted; Within, Across, Last, EOY, LTR and LTRL. In the bottom row of the table we present tests for AR and ARCH effects in the residual. Specifically, the p-values for Ljung-Box Q-statistics for residual autocorrelation of up to order 3 and for $\mathrm{ARCH}(1)$ effects are provided. Estimation was done with the RATS software package and implemented with the 'Maximize' function including the 'Robust' option for heteroscedasticity/misspecification adjusted standard errors. 


\begin{tabular}{|c|c|c|c|c|c|c|c|c|c|}
\hline \multirow[b]{2}{*}{ Regression } & \multicolumn{3}{|c|}{ Dependent: $\dot{P}^{a u c}$} & \multicolumn{6}{|c|}{ Dependent: $\dot{Q}^{a u c}$} \\
\hline & (1) & $(2)$ & $(3)$ & $(4)$ & $(5)$ & (6) & (7) & (8) & (9) \\
\hline Period & Crisis I & Crisis I & Crisis I & Crisis I & Crisis I & Crisis I & Crisis II & Crisis II & Crisis II \\
\hline $\bar{R}^{2}$ & 0.106 & 0.13 & 0.117 & 0.471 & 0.467 & 0.467 & 0.031 & 0.045 & 0.047 \\
\hline D-W Statistic & 1.847 & 1.853 & 1.853 & 1.963 & 1.973 & 1.981 & 1.988 & 1.988 & 2.061 \\
\hline $\begin{array}{l}\text { F-Test Exclusions } \\
\text { Significance Level }\end{array}$ & & $\begin{array}{r}0.394 \\
{[0.812]}\end{array}$ & $\begin{array}{r}0.794 \\
{[0.557]}\end{array}$ & & $\begin{array}{r}1.235 \\
{[0.302]}\end{array}$ & $\begin{array}{r}2.467 \\
{[0.051]}\end{array}$ & & $\begin{array}{r}0.081 \\
{[0.995]}\end{array}$ & \\
\hline Constant & $\begin{array}{l}1.889 \\
(1.546)\end{array}$ & $\begin{array}{r}1.557^{\bar{*}} \\
(0.685)\end{array}$ & $\begin{array}{r}1.490^{\bar{*}} \\
(0.683)\end{array}$ & $\begin{array}{c}-1.501 \\
(2.831)\end{array}$ & & & $\begin{array}{c}-4.185 \\
(2.787)\end{array}$ & $\begin{array}{r}-3.517^{\bar{*}} \\
(1.741)\end{array}$ & $\begin{array}{r}-3.549^{\bar{*}} \\
(1.755)\end{array}$ \\
\hline Year End & $\begin{array}{r}-17.806^{\bar{*}} \\
(5.432)\end{array}$ & $\begin{array}{r}-16.768^{\bar{*}} \\
(4.944)\end{array}$ & $\begin{array}{r}-14.770^{\bar{*}} \\
(4.815)\end{array}$ & $\begin{array}{r}63.153^{\bar{*}} \\
(9.941)\end{array}$ & $\begin{array}{r}60.091^{\bar{*}} \\
(9.429)\end{array}$ & $\begin{array}{r}58.168^{\bar{*}} \\
(9.207)\end{array}$ & $\begin{array}{c}0.594 \\
(6.423)\end{array}$ & & \\
\hline Year Start & $\begin{array}{l}2.337 \\
(5.074)\end{array}$ & & & $\begin{array}{r}-11.867 \\
\quad(9.273)\end{array}$ & & & $\begin{array}{c}2.457 \\
(6.628)\end{array}$ & & \\
\hline$L A S T_{t}$ & $\begin{array}{c}0.28 \\
(2.546)\end{array}$ & & & $\begin{array}{r}22.181^{\bar{*}} \\
(4.783)\end{array}$ & $\begin{array}{r}20.475^{\bar{*}} \\
(3.679)\end{array}$ & $\begin{array}{l}20.613^{\bar{*}} \\
(3.678)\end{array}$ & $\begin{array}{l}12.213^{\bar{*}} \\
(4.294)\end{array}$ & $\begin{array}{r}11.638^{\bar{*}} \\
(3.748)\end{array}$ & $\begin{array}{l}11.719^{\bar{*}} \\
(3.721)\end{array}$ \\
\hline$L T R O_{t}$ & $\begin{array}{l}0.527 \\
(2.19)\end{array}$ & & & $\begin{array}{c}4.297 \\
(4.135)\end{array}$ & & & $\begin{array}{c}0.564 \\
(3.278)\end{array}$ & & \\
\hline$L T R O_{t-1}$ & $\begin{array}{c}-1.892 \\
(2.104)\end{array}$ & & & $\begin{array}{r}-5.834 \\
(3.923)\end{array}$ & $\begin{array}{r}-6.942^{\bar{*}} \\
(2.777)\end{array}$ & $\begin{array}{r}-6.796^{\bar{*}} \\
(2.774)\end{array}$ & $\begin{array}{r}5.467^{*} \\
(3.279)\end{array}$ & $\begin{array}{r}5.08^{*} \\
(2.787)\end{array}$ & $\begin{array}{r}5.089^{*} \\
(2.743)\end{array}$ \\
\hline$\dot{Q}_{t}^{\text {repo }}$ & $\begin{array}{r}-0.294^{\bar{*}} \\
(0.125)\end{array}$ & $\begin{array}{r}-0.256^{\bar{*}} \\
(0.12)\end{array}$ & $\begin{array}{r}-0.273^{\bar{*}} \\
(0.12)\end{array}$ & $\begin{array}{c}-0.192 \\
(0.238)\end{array}$ & $\begin{array}{l}-0.26 \\
(0.229)\end{array}$ & $\begin{array}{c}-0.232 \\
(0.228)\end{array}$ & $\begin{array}{l}0.058 \\
(0.131)\end{array}$ & & \\
\hline$\dot{Q}_{t-1}^{r e p o}$ & $\begin{array}{c}-0.138 \\
(0.119)\end{array}$ & $\begin{array}{c}-0.165 \\
(0.106)\end{array}$ & & $\begin{array}{c}0.1 \\
(0.224)\end{array}$ & $\begin{array}{l}0.203 \\
(0.205)\end{array}$ & & $\begin{array}{c}0.013 \\
(0.128)\end{array}$ & & \\
\hline$\dot{Q}_{t-2}^{r e p o}$ & & & & & & & $\begin{array}{r}0.337^{\bar{*}} \\
(0.128)\end{array}$ & $\begin{array}{c}0.328^{\bar{*}} \\
(0.125)\end{array}$ & $\begin{array}{r}0.328^{\bar{*}} \\
(0.125)\end{array}$ \\
\hline$\rho_{\text {auc }}$ & $\begin{array}{r}-0.135 \\
(0.13)\end{array}$ & $\begin{array}{c}-0.169 \\
(0.124)\end{array}$ & $\begin{array}{r}-0.180 \\
(0.125)\end{array}$ & $\begin{array}{r}-0.206^{*} \\
(0.107)\end{array}$ & $\begin{array}{c}-0.174 \\
(0.105)\end{array}$ & $\begin{array}{c}-0.162 \\
(0.104)\end{array}$ & $\begin{array}{c}-0.029 \\
(0.056)\end{array}$ & $\begin{array}{c}-0.031 \\
(0.056)\end{array}$ & \\
\hline
\end{tabular}

Table 2: The tabulated results are for regressions explaining the auction outcomes. The number of observations is 98 and 329 for Crisis I and Crisis II respectively. The Crisis I period is 19th June 2007 to 7 th September 2008 and the Crisis II period is from 16th Dec 2008 to 30th Jan 2013. For the case of the weighted average settlement rate, $\dot{P}^{a u c}$, we selected regression (3) as the preferred specification. For the case of allotment quantity, $\dot{Q}^{a u c}$, we selected regression (5) as the preferred specification for Crisis I and regression (9) for Crisis II. The residuals from the preferred specifications are used in the repo volume regressions considered in the following table. Coefficient estimates are displayed with standard errors in parentheses $(\overline{\bar{*}}, \bar{*}$ and $*$ respectively indicate sizes of the underlying p-values as follows; $p<0.01,0.01<p<0.05$ or $0.05<p<0.10$ ). The $\bar{R}^{2}$ and Durbin Watson statistic are shown in the top panel. The F-statistics and associated significance levels are also provided for the joint test of exclusion restrictions implied by regressions 2 and 3 relative to regression 1, regressions 5 and 6 relative to regression 4, and regression 8 relative to regression 7 . 


\begin{tabular}{|c|c|c|c|c|c|c|c|c|c|c|}
\hline \multirow[b]{2}{*}{ Regression } & \multicolumn{10}{|c|}{ Dependent: $\dot{Q}^{\text {Repo }}$} \\
\hline & (1) & $(2)$ & (3) & & (4) & (5) & (6) & (7) & (8) & (9) \\
\hline Period & Crisis I & Crisis I & Crisis I & & Crisis I & Crisis I & Crisis I & Crisis II & Crisis II & Crisis II \\
\hline $\bar{R}^{2}$ & 0.437 & 0.473 & 0.470 & & 0.493 & 0.513 & 0.502 & 0.053 & 0.073 & 0.067 \\
\hline D-W Statistic & 2.051 & 2.042 & 2.029 & & 2.028 & 2.023 & 2.172 & 1.998 & 1.999 & 1.900 \\
\hline $\begin{array}{l}\text { F-Test Exclusions } \\
\text { Significance Level }\end{array}$ & & $\begin{array}{r}0.450 \\
{[0.916]}\end{array}$ & $\begin{array}{r}0.519 \\
{[0.885]}\end{array}$ & & & $\begin{array}{r}0.674 \\
{[0.745]}\end{array}$ & $\begin{array}{r}0.658 \\
{[0.773]}\end{array}$ & & $\begin{array}{r}0.324 \\
{[0.974]}\end{array}$ & $\begin{array}{r}0.327 \\
{[0.979]}\end{array}$ \\
\hline Resid: $\dot{P}_{t-1}^{a u c}$ & $\begin{array}{c}0.363^{\overline{\bar{*}}} \\
(0.095)\end{array}$ & $\begin{array}{r}0.362^{\overline{\bar{*}}} \\
(0.089)\end{array}$ & $\begin{array}{r}0.372^{\overline{\bar{*}}} \\
(0.089)\end{array}$ & & $\begin{array}{c}0.431^{\overline{\bar{*}}} \\
(0.089)\end{array}$ & $\begin{array}{c}0.408^{\overline{\bar{*}}} \\
(0.085)\end{array}$ & $\begin{array}{r}0.4^{\overline{\bar{*}}} \\
(0.085)\end{array}$ & & & \\
\hline Resid: $\dot{Q}_{t-1}^{a u c}$ & $\begin{array}{r}-0.026 \\
(0.044)\end{array}$ & $\begin{array}{c}-0.025 \\
(0.041)\end{array}$ & & & $\begin{array}{r}-0.037 \\
(0.044)\end{array}$ & $\begin{array}{r}-0.031 \\
(0.041)\end{array}$ & & $\begin{array}{c}-0.013 \\
(0.024)\end{array}$ & $\begin{array}{r}-0.014 \\
(0.023)\end{array}$ & \\
\hline$\triangle C D S_{D E}^{B a n k}$ & $\begin{array}{r}-25.181^{\bar{*}} \\
(12.587)\end{array}$ & $\begin{array}{r}-25.494^{\bar{*}} \\
(11.489)\end{array}$ & $\begin{array}{r}-28.209^{\bar{*}} \\
(11.563)\end{array}$ & $\triangle$ Spread $_{D E}$ & $\begin{array}{c}2.691^{*} \\
(1.578)\end{array}$ & $\begin{array}{c}2.465^{*} \\
(1.382)\end{array}$ & $\begin{array}{c}2.633^{*} \\
(1.344)\end{array}$ & $\begin{array}{c}-2.339 \\
(2.712)\end{array}$ & & \\
\hline$\triangle C D S_{E S}^{B a n k}$ & $\begin{array}{c}15.479 \\
(10.554)\end{array}$ & $\begin{array}{c}12.877 \\
(9.795)\end{array}$ & & $\triangle$ Spread $_{E S}$ & $\begin{array}{r}-1.199 \\
(1.264)\end{array}$ & & & $\begin{array}{c}0.466 \\
(1.865)\end{array}$ & & \\
\hline$\triangle C D S_{G R}^{B a n k}$ & & & & $\triangle$ Spread $_{G R}$ & $\begin{array}{r}-1.213 \\
(1.425)\end{array}$ & & & $\begin{array}{c}3.025^{*} \\
(1.535)\end{array}$ & $\begin{array}{c}3.158^{\bar{*}} \\
(1.471)\end{array}$ & $\begin{array}{r}3.307^{\bar{*}} \\
(1.493)\end{array}$ \\
\hline$\triangle C D S_{I E}^{B a n k}$ & $\begin{array}{c}9.864 \\
(6.145)\end{array}$ & $\begin{array}{c}11.418^{*} \\
(5.831)\end{array}$ & $\begin{array}{c}11.281^{*} \\
(5.902)\end{array}$ & $\triangle$ Spread $_{I E}$ & $\begin{array}{r}-0.162 \\
(0.953)\end{array}$ & & & $\begin{array}{c}-1.513 \\
(2.018)\end{array}$ & & \\
\hline$\triangle C D S_{I T}^{\text {Bank }}$ & $\begin{array}{r}34.755^{\bar{*}} \\
(14.353)\end{array}$ & $\begin{array}{r}31.963^{\bar{*}} \\
(12.838)\end{array}$ & $\begin{array}{r}29.482^{\bar{*}} \\
(11.526)\end{array}$ & $\triangle$ Spread $_{I T}$ & $\begin{array}{r}-4.833^{*} \\
(2.823)\end{array}$ & $\begin{array}{r}-6.511^{\bar{*}} \\
(2.486)\end{array}$ & $\begin{array}{r}-6.889^{\overline{\bar{*}}} \\
(2.46)\end{array}$ & $\begin{array}{r}-2.192^{\bar{*}} \\
(0.926)\end{array}$ & $\begin{array}{r}-2.138^{\bar{*}} \\
(0.867)\end{array}$ & $\begin{array}{r}-1.888^{*} \\
(0.873)\end{array}$ \\
\hline$\triangle C D S_{P T}^{B a n k}$ & $\begin{array}{r}-25.625^{*} \\
(13.121)\end{array}$ & $\begin{array}{r}-20.566^{*} \\
(12.166)\end{array}$ & & $\triangle$ Spread $_{P T}$ & $\begin{array}{r}-2.676^{\bar{*}} \\
(1.219)\end{array}$ & $\begin{array}{r}-2.408^{\bar{*}} \\
(1.129)\end{array}$ & $\begin{array}{r}-2.606^{\bar{*}} \\
(1.106)\end{array}$ & $\begin{array}{c}2.335 \\
(2.175)\end{array}$ & & \\
\hline$\triangle C D S_{D E}^{S o v}$ & $\begin{array}{r}-2.485 \\
(4.517)\end{array}$ & & & $\triangle Q_{D E}^{A s k}$ & $\begin{array}{r}-13.695^{\bar{*}} \\
(4.5)\end{array}$ & $\begin{array}{r}-12.817^{\bar{*}} \\
(3.545)\end{array}$ & $\begin{array}{r}-10.707^{\bar{*}} \\
(3.493)\end{array}$ & $\begin{array}{r}-10.203^{\bar{*}} \\
(5.025)\end{array}$ & $\begin{array}{r}-9.577^{\bar{*}} \\
(4.831)\end{array}$ & $\begin{array}{r}-7.968 \\
(4.867)\end{array}$ \\
\hline$\triangle C D S_{E S}^{S o v}$ & $\begin{array}{c}1.901 \\
(8.866)\end{array}$ & & & $\triangle Q_{E S}^{A s k}$ & $\begin{array}{c}3.355 \\
(3.433)\end{array}$ & & & $\begin{array}{c}4.369 \\
(5.448)\end{array}$ & & \\
\hline$\triangle C D S_{G R}^{S o v}$ & $\begin{array}{c}10.285 \\
(14.409)\end{array}$ & & & $\triangle Q_{G R}^{A s k}$ & $\begin{array}{r}-7.784 \\
(5.241)\end{array}$ & & & $\begin{array}{c}-1.183 \\
(3.082)\end{array}$ & & \\
\hline$\triangle C D S_{I E}^{S o v}$ & $\begin{array}{r}-1.772 \\
(5.227)\end{array}$ & & & $\triangle Q_{I E}^{A s k}$ & $\begin{array}{c}-4.4 \\
(4.009)\end{array}$ & & & $\begin{array}{r}-1.375 \\
(3.852)\end{array}$ & & \\
\hline$\triangle C D S_{I T}^{S o v}$ & $\begin{array}{r}46.376^{\bar{*}} \\
(22.679)\end{array}$ & $\begin{array}{r}53.34^{\bar{*}} \\
(19.576)\end{array}$ & $\begin{array}{r}58.913^{\bar{*}} \\
(19.313)\end{array}$ & $\triangle Q_{I T}^{A s k}$ & $\begin{array}{r}-8.942^{\bar{*}} \\
(3.934)\end{array}$ & $\begin{array}{r}-8.963^{\bar{*}} \\
(3.653)\end{array}$ & $\begin{array}{r}-8.367^{\bar{*}} \\
(3.487)\end{array}$ & $\begin{array}{c}0.565 \\
(2.659)\end{array}$ & & \\
\hline$\triangle C D S_{P T}^{S o v}$ & $\begin{array}{r}-39.834^{*} \\
(21.508)\end{array}$ & $\begin{array}{r}-39.659^{\bar{*}} \\
(18.949)\end{array}$ & $\begin{array}{r}-45.679^{\bar{*}} \\
(18.561)\end{array}$ & $\triangle Q_{P T}^{A s k}$ & $\begin{array}{r}-1.682 \\
(5.056)\end{array}$ & & & $\begin{array}{c}11.047^{\bar{*}} \\
(5.297)\end{array}$ & & $\begin{array}{r}10.596^{\bar{*}} \\
(4.835)\end{array}$ \\
\hline $\begin{array}{l}\triangle E U R I B \\
-O I S\end{array}$ & $\begin{array}{r}-1.582 \\
(1.746)\end{array}$ & & & $\begin{array}{l}\triangle E U R I B \\
-O I S\end{array}$ & $\begin{array}{r}-1.242 \\
(1.877)\end{array}$ & & & $\begin{array}{c}1.441 \\
(0.893)\end{array}$ & & $\begin{array}{r}1.456^{*} \\
(0.861)\end{array}$ \\
\hline$\rho_{\text {repo }}$ & $\begin{array}{r}-0.107 \\
(0.122)\end{array}$ & $\begin{array}{r}-0.098 \\
(0.115)\end{array}$ & & & $\begin{array}{r}-0.176 \\
(0.121)\end{array}$ & $\begin{array}{r}-0.125 \\
(0.107)\end{array}$ & & $\begin{array}{c}0.069 \\
(0.059)\end{array}$ & & \\
\hline
\end{tabular}

Table 3: Results for pre- and post-Lehman periods are shown (the regression is described in Section 3.2). There 98 and 329 observations in the pre- and post-Lehman periods respectively. The pre-Lehman period runs from 19th June 2007 to 7th September 2008 and the post-Lehman period runs from 16th Dec 2008 to 30th Jan 2013. Standard errors are in parentheses $(\bar{*}, \bar{*}$ and $*$ respectively indicate sizes of p-values as follows; $p<0.01,0.01<p<0.05$ or $0.05<p<0.10)$. Coefficients of additive dummy variables are not shown. $\bar{R}^{2}$ and Durbin Watson statistics are shown in the top panel. The F-statistics and their significance are provided for exclusion restrictions implied by regressions 2 and 3 relative to 1 , regressions 5 and 6 relative to 4 , and regressions 8 and 9 relative to 7 . 